\title{
Advanced yolk-shell nanoparticles as nanoreactors for energy conversion
}

\author{
Meiwen Wang, Yash Boyjoo, Jian Pan, Shaobin Wang\#, Jian Liu * \\ Department of Chemical Engineering, Curtin University, Perth, WA 6845, Australia
}

\section{A R T I C L E I N F}

\section{Article history:}

Received 28 October 2016

Accepted 13 March 2017

Published 5 June 2017

\section{Keywords:}

Yolk-shell nanoreactors

Energy conversion applications

Photocatalysis

Fuel cell

Utilization of carbon sources

\begin{abstract}
A B S T R A C T
Yolk-shell structured nanoparticles are of immense scientific and technological interests because of their unique architecture and myriad of applications. This review summarizes recent progresses in the use of yolk-shell structured nanoparticles as nanoreactors for various chemical reactions. A very brief overview of synthetic strategies is provided with emphasis on recent research progress in the last five years. Catalytic applications of these yolk-shell structured nanoreactors are then discussed by covering photocatalysis, methane reforming and electrochemical conversion. The state of the art research and perspective in future development are also highlighted.
\end{abstract}

(C) 2017, Dalian Institute of Chemical Physics, Chinese Academy of Sciences. Published by Elsevier B.V. All rights reserved.

\section{Introduction}

smartest way; this has provided inspiration for many artificial materials and processes. Nanoreactors first appeared in the 1990s and became good potential candidates for catalytic applications [2]. Nanoreactors replicate the mechanisms of natural catalysts such as enzymes, bacteria, and cellular organelles in boosting reaction rates and production yields. Nanoreactors have several advantages over conventional ones, such as the ability to perform parallel chemical reactions, the elimination of undesirable products, and enhancement of the catalytic performance as a result of large surface:volume ratios. Researchers have therefore devoted much effort to understanding and investigating nanoreactors, especially the relationship between nanoarchitecture and catalytic performance.

High energy demands, limited natural fossil fuel reserves, and the environmental consequences of energy generation are causing great concern globally; therefore much current scientific research is focused on sustainable energy generation. Average energy consumption is increasing because of the in-

\footnotetext{
* Corresponding author. E-mail: jian.liu@curtin.edu.au

\# Corresponding author. E-mail: shaobin.wang@exchange.curtin.edu.au

DOI: 10.1016/S1872-2067(17)62818-3 | http://www.sciencedirect.com/science/journal/18722067 | Chin. J. Catal., Vol. 38, No. 6, June 2017
} 
creasing global population and development of new technologies. Although the idea of using renewable energy to replace conventionally produced energy arose decades ago, low efficiency, high capital costs, and environmental consequences are challenges that have yet to be tackled. In recent years, catalytic energy conversion, which involves transformation of energy from one form to another or of wastes to valuable products, has become an attractive method for solving these problems. Energy-conversion techniques such as the use of carbon resources, solar energy conversion, and electrochemical fuel cells have the potential to resolve current difficulties. In terms of catalysis, nanoscale catalysts show enhanced catalytic activities and stabilities, which are essential characteristics for chemical reactions. Among the latest nanocatalysts for energy conversion, catalysts with advanced structures outperform traditional ones, and yolk-shell-structured catalysts give the best performances.

Yolk-shell nanoparticles (YSNs) or "nanorattles" have attracted much attention because of their unique structures and enhanced performances in a wide range of applications, including catalysis, energy storage and conversion, environmental remediation, and nanomedicine [3-8]. In principle, a yolk-shell structure is an advanced development of a core-shell structure with a core@void@shell configuration (Fig. 1(A)); such structures have high surface-area-to-volume ratios [3-8]. Recently, an extensive range of materials have been used to develop yolk-shell-structured nanoparticles to fulfil different needs in various applications. Generally, YSNs have a metal or metal oxide core that is encapsulated in inorganic or polymer shells of various shapes. Silica and carbon are the commonest shell materials because of their simple functionality, high biocompatibility, stability, and abundance [9-12]. Conducting polymers are also good shell materials because of their inertness and high conductivity and, most importantly, the possibility of tailoring their functional groups [13]. There are many significant variations that can be used to improve the performances and mechanical strengths of YSNs, such as changing the dimension, shell thickness, size uniformity, and nanoparticle shape. Various methods have been developed for synthesizing YSNs with tuneable parameters. These methods include selec-

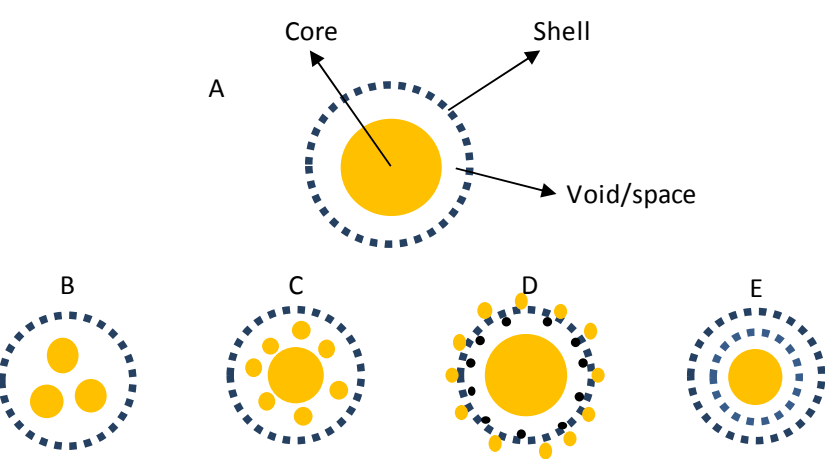

Fig. 1. Diagram of different spherical architectures of YSNs. (A) core encapsulated in shell; (B) multiple cores within solid shell; (C) core-satellite-shell structure; (D) single yolk encapsulated in shell with multiple cores loaded on shell surface; (E) single core within multiple shells. tive etching, soft templating (or bottom-up methods), hard templating, ship-in-a-bottle, Ostwald ripening, galvanic replacement, and use of the Kirkendall effect.

Catalysts should have certain characteristics, including long life, reusability, and high catalytic activity, selectivity, and stability, even in harsh environments [3,5,14-16]. All these requirements can be satisfied by yolk-shell structures because the YSN core, which is usually the active site for the catalytic reaction, is protected by a shell, and this prevents decay during catalytic reactions $[4,6,17]$. Moreover, in many cases, the shells of YSNs are porous and permeable, allowing sufficient diffusion of reactants in and out of the YSNs through the nanoporous channels, while protecting the metal core from aggregation and sintering $[10,18,19]$. The advantages of YSNs as nanoreactors can be summarized as: (1). the manipulable physical and chemical properties of the core and shell; (2). a movable core within the shell for cooperative catalysis; (3). a homogeneous reaction environment for heterogeneous catalysis because the voids act as a reservoir; (4). protection of the catalytic core nanoparticles and suppression of agglomeration; and (5). controllable diffusion rates [3-7,20-29]. Recently, the structures of YSNs have been intensively investigated and have been shown to greatly affect the catalytic performances. Furthermore, the successes achieved using YSNs have led to the rapid development of YSNs with increasingly complex architectures. These YSN architectures can be briefly categorized as: (1). a single core encapsulated in a shell (Fig. 1(A)); (2). multiple cores within a shell (Fig. 1(B) and (C)); (3). a single yolk encapsulated in a shell with multiple cores loaded on the shell surface (Fig. 1(D)); and (4). a single core within multiple shells (Fig. 1(E)) $[3,5,24,30,31]$. Among these, a single core within a single shell is the most basic YSN structure and can be achieved using numerous methods. The other YSN structures are generally derived from this basic structural concept. YSNs with multiple cores within a porous shell are favoured because the contact surface area provided by multicores is larger than that provided by a single core, reactant transfer into and out of the core is easier, the catalytic activities are higher, and multiple cores can be either of uniform (Fig. 1(B)) or different sizes (Fig. 1(C)) [32]. A single yolk within a capsule with multiple metal nanoparticles loaded on the shell surface is another category (Fig. 1(D)). The multiple metal nanoparticles serve as active sites that are different from those in the central yolk. This architecture enables more than one catalytic reaction to be performed and enhances the catalytic performance. A more advanced YSN structure consists of multiple shells with a single core (Fig. 1(E)). Multiple-shell nanoparticles have higher loading capacities and larger surface areas than single-shell nanoparticles [24]. This structure is generally used for multistep catalytic reactions, and all the materials involved in such nanoparticles must be highly selective to avoid unwanted by-products $[24,33]$. The best YSN structure cannot be defined because every chemical reaction has its own needs, and the optimum composition, shape, and structure can only be determined based on the YSN performance.

Some examples of the use of YSNs as nanoreactors are as follows. Au@ $\mathrm{ZrO}_{2}$ performed well in CO oxidation; $\mathrm{Pd@SiO} 2$ 
gave a very high production yield (99.5\%) in Suzuki coupling reactions; $\mathrm{Ni@SiO} 2$ showed high catalytic activity in steam methane reforming; Au nanoparticles in a permeable carbon shell (Au@HCS) provided an efficient catalyst for the reduction of 4-nitrophenol by $\mathrm{NaBH}_{4}$ to 4-aminophenol [18,20,21,34].

Many of the published reviews focus on brief synopses of an extensive range of applications of YSNs, mostly silica-based YSNs. In contrast, in this review, we give a detailed summary of basic methods for YSN synthesis as well as recent advances in applications of YSNs as nanoreactors for energy conversion, with extensive coverage of yolk-shell compositions. Energy-conversion applications include methane reforming, photosynthesis, and electrocatalysis, which are popular and important energy-conversion techniques. Yolk-shell nanotechnology is a relatively new field; therefore many applications are not yet well developed. However, based on the rapid growth of interest in YSN applications, this review brings together the latest achievements in yolk-shell nanoreactors for catalysis, which will contribute greatly to our fundamental understanding and enable further developments.

\section{Synthetic methods}

\subsection{General synthetic methods}

Yolk-shell nanoreactors have great potential for use in an extensive range of applications; therefore many synthetic methods for the preparation of various YSNs have been developed. Different methods are used to obtain specific compositions, architectures, and dimensions. All these approaches have common characteristics: e.g. they are easy to perform, effective, economically viable, and environmentally friendly. Selective etching, soft templating (bottom-up methods), hard templating, ship-in-a-bottle, Ostwald ripening, galvanic replacement, and the Kirkendall diffusion method (Fig. 2) are general methods for YSN synthesis $[3,20]$. In this section, we will briefly intro-

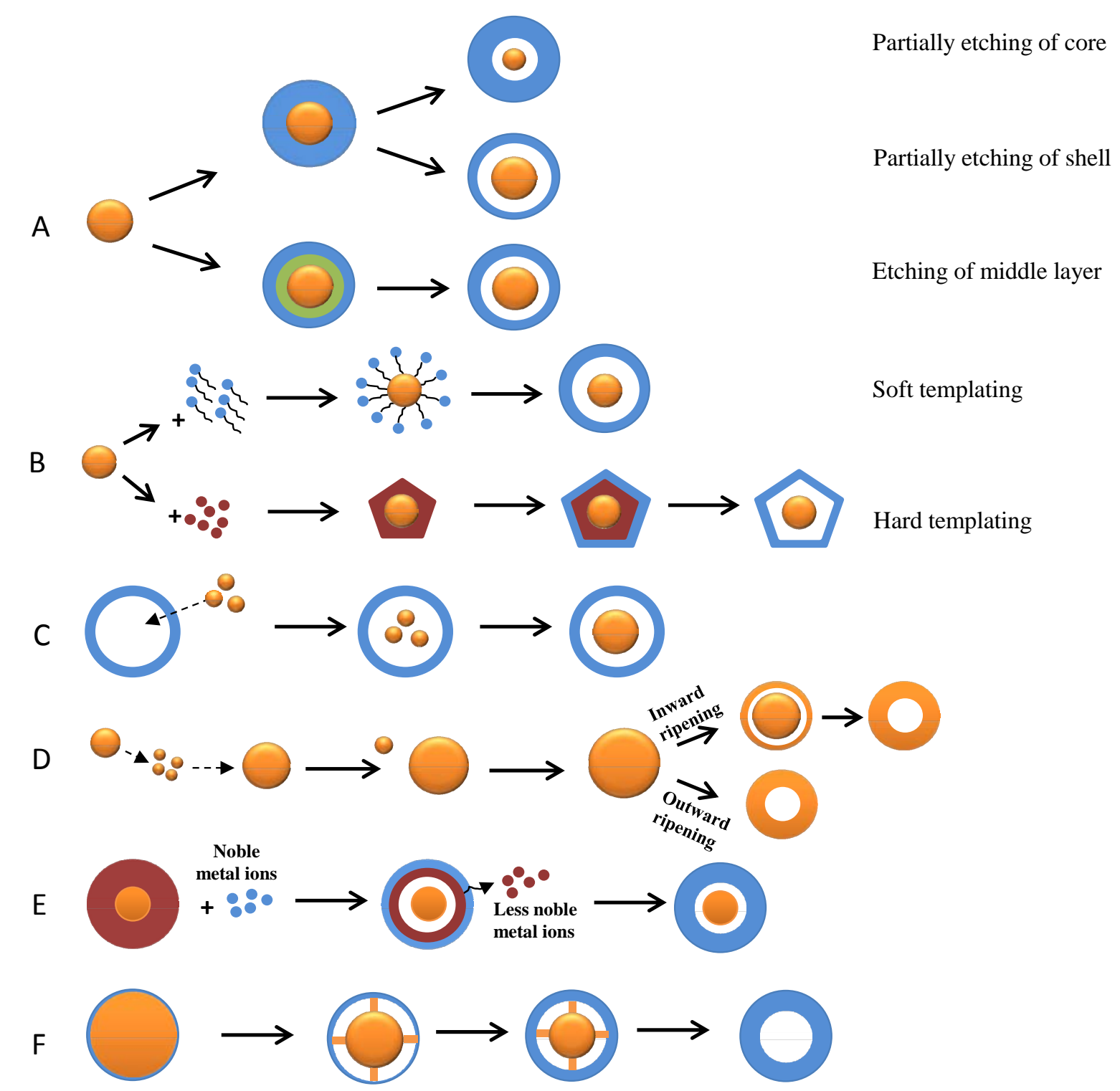

Fig. 2. Simple diagrams of general synthetic methods. (A) selective etching method; (B) soft- and hard-templating methods; (C) ship-in-a-bottle method; (D) Ostwald ripening method; (E) galvanic replacement method; (F) Kirkendall diffusion method. 
duce each method and compare them.

Selective etching uses chemicals or calcination to selectively remove either part of the shell or part of the core to create a void between the core and the shell, as shown in Fig. 2(A). There are three types of selective etching method: partial etching, surface-protected etching, and shell formation via chemical reactions [3]. The first method, partial etching, is one of the commonest fabrication routes because of its simplicity. Generally, a void is created by introducing a certain amount of an acidic or basic etchant (such as $\mathrm{HF}$ or $\mathrm{NaOH}$ ) to partially etch out core or shell material. The core size and shell thickness can be tuned by adjusting the amount of etchant used. The second method, surface-protected etching, was first developed in 2007 [3]. Many researchers have stated that this strategy was a significant breakthrough in synthesizing porous silica nanoparticles. For sol-gel-derived silica nanoparticles, the dense silica layer makes it difficult for outside molecules to reach the inner active core; surface-protected etching overcomes this drawback [35]. In this method, the surfaces of metal oxide (such as silica) particles are coated with a protecting layer such as poly(vinylpyrrolidone) [35] and 3-thiocyanatopropyltriethoxysilane [36] and then an appropriate etchant is introduced to etch away part of the metal oxide from the interior and create a porous shell structure at the same time. This protecting layer enables the metal oxide nanoparticles to retain their original size, while creating voids [35].

In the third selective etching method, formation of the shell material through chemical reactions between core and shell materials is a spontaneous self-formation method. First, a core (pure metal or metal oxide) coated with a shell (pure metal or metal oxide) in a core-shell structure is prepared. Selective etching occurs when the shell reacts with the core to create a void between the core and shell. This synthetic method is not popular because it is only suitable for a limited number of nanoparticle compositions.

Soft templating is a flexible, simple, and effective method, especially for the fabrication of functional YSNs with porous shells [20]. Soft templates are surfactants and polymers which have a hydrophilic head and hydrophobic chain [15]. When noble metal cores are evenly dispersed in a soft template mixture, the soft templates spontaneously attach to the cores to give well-defined assemblies under certain conditions to form core-shell nanoparticles. Hydrolysis and condensation of the core-shell nanoparticles remove the hydrophobic chains and form a space between the core and the shell. YSNs are obtained by calcination to produce a porous shell, as shown in Fig. 2(B) [15].

Hard templating is performed similarly to soft templating, but hard templates instead of soft templates spontaneously attach to the core material. The hard-templating method performs well in the synthesis of rigid YSNs with a movable core encapsulated in a hollow metal oxide shell [15]. A presynthesized metal core is coated with a hard template and then the desired shell material attaches to the hard template layer to form sandwich-structured core-shell nanoparticles. Finally, an etchant is introduced to remove the hard template and create a void between the shell and the core.
Ship-in-a-bottle methods involve entrapment of molecules in nanocapsules; the method is the reverse of the usual YSN methods such as selective etching or soft templating [22]. In this synthesis route, a porous hollow nanoshell or nanocage is prepared first. Core precursors/molecules then enter the shell through channels in the porous shell. The core precursors/molecules then assemble to form single or multiple cores inside the hollow chamber, as shown in Fig. 2(C).

Ostwald ripening is a physical recrystallization process and does not involve any chemical reaction. According to the International Union of Pure and Applied Chemistry, Ostwald ripening is "the growth of larger crystals from those of smaller sized ones which have a higher solubility" $[3,37,38]$. Recently, a new Ostwald ripening mechanism was developed. It can be described as an oriented attachment process in which small crystals attach to each other in the correct orientation to form bigger crystals [39]. This new method has been used in many research studies. The Ostwald ripening method is a thermodynamically favourable and spontaneous template-free strategy for creating yolk-shell or hollow nanoparticles [40]. Unstable and less dense smaller nanocrystals with higher solubilities have a strong tendency to dissolve and redeposit on the surface through a recrystallization process, which leaves a hollow interior space, as shown in Fig. 2(D) [40,41]. The formation of YSNs is driven by the differences among the chemical potentials of the crystallites $[3,42]$.

Galvanic replacement, which is a sacrificial template strategy, is an efficient and easy route for synthesizing YSNs with controllable morphologies, particularly controlled compositions and porosities $[3,43,44]$. Many researchers consider galvanic replacement to be the most versatile synthetic method. The mechanism of galvanic replacement is based on a redox chemical reaction in which the metal from a metal salt is exchanged with metal ions from solution because of their different electrochemical potentials, as shown in Fig. 2(E). The less noble metal from the metal salt nanoparticle is the sacrificial template and acts as a reducing agent; it is concurrently replaced by a more noble metal ion from the solution to achieve electrochemical potential equilibrium $[45,46]$. Galvanic replacement involves deposition of a more noble metal, alloying, and dissolution of a less noble metal. Dissolution of the less noble metal forms pinholes, which result in voids, and these expand towards the centre [44].

Kirkendall diffusion is another ion-exchange method for nanoparticle synthesis after galvanic replacement and also a crystal growth synthetic method besides Ostwald ripening $[37,42]$. Kirkendall mass transfer occurs at the boundary of two different metals when an imbalance in their diffusion rates occurs, leaving vacancies at the material side with the faster diffusion rate [47]. In YSN synthesis based on Kirkendall diffusion, a core-shell nanoparticle consisting of two different core and shell materials (metal or alloy) is first prepared. Usually, the core material is the sacrificial template and has a faster diffusion rate than the shell material. Voids are formed at the core/shell interface via thermal activation (Fig. 2(F)) [44]. Further diffusion leads to formation of a hollow nanoparticle structure. 


\subsection{Comparison and analysis of general synthetic methods}

As discussed in Table 1, selective etching is one of the most popular methods for YSN fabrication and is suitable for synthesizing an extensive range of materials, especially silica- and carbon-based nanoparticles. Among selective etching approaches, surface-protected strategies are commonly used for fabricating hollow and non-spherical structures. Fine tuning the amount of etchants and surfactants enables control of the nanoparticle size and shell thickness. However, this is one of the main drawbacks of this method because the appropriate amounts of etchants and surfactants need to be determined by trial and error. The low uniformity of the nanoparticle size is another weakness. Selective etching is therefore not recommended for producing high-quality YSNs with a narrow size distribution. These problems can be solved by using a combination of selective etching and other synthetic methods.

Here, we briefly introduce some examples to elaborate the selective etching steps. One-component YSNs, namely silica@mesoporous silica $\left(\mathrm{SiO}_{2} @ \mathrm{~m}-\mathrm{SiO}_{2}\right)$, with dense silica nanospherical cores were first prepared using the Stöber method. A sol-gel method with pore-forming agents was used to coat the silica nanospheres with a mesoporous silica layer to form a core-shell structure [51]. The absence and presence of surfactants in the silica core and mesoporous silica shell resulted in structural differences; therefore etchants such as $\mathrm{Na}_{2} \mathrm{CO}_{3}$ or ammonia solution selectively etched part of the core material to form voids between the cores and shells. Surfactants were removed by high-temperature treatment [51]. Two-component YSNs, Au@m-SiO 2 , were prepared as follows. Au nanoparticles were prepared by traditional sodium citrate reduction and then the metal spheres were coated with a layer of dense silica via a sol-gel method. A mesoporous silica shell was deposited outside the dense silica layer to form a Au@SiO ${ }_{2} @ m-\mathrm{SiO}_{2}$ core-shell structure [51]. A Au@m- $\mathrm{SiO}_{2}$ yolk-shell structure was created by introducing an etchant to etch away the dense silica layer. Three-component $\mathrm{YSN}_{3}, \mathrm{Fe}_{3} \mathrm{O}_{4} @ \mathrm{SiO}_{2} @ \mathrm{TiO}_{2}$, were synthesized using a surface-protected selective etching method. Each $\mathrm{Fe}_{3} \mathrm{O}_{4}$ sphere was coated with a layer of silica, followed by a layer of resorcinol-formaldehyde (RF) resin, and an outer layer of amorphous $\mathrm{TiO}_{2}$, using sol-gel processes, to form a $\mathrm{FeO}_{4} @ \mathrm{SiO}_{2} @ \mathrm{RF} @ \mathrm{TiO}_{2}$ core-shell structure [52]. The core-shell nanoparticles then underwent two-step annealing treatment. During the first calcination under nitrogen, a carbon layer was formed, which protected the precrystallized $\mathrm{TiO}_{2}$ shell from morphological changes. A yolk-shell structure was created by removing the carbon layer through calcination in air [52].

Soft-templating methods overcome many of the difficulties associated with selective etching, such as multiple steps and the need for accurate amount of etchants. Soft templates such as surfactants, polymers, and viruses can be easily removed via simple processes such as washing and calcination, without using chemicals, in contrast to hard templates. Soft templating is therefore the perfect option for one-pot synthetic strategies $[15,29]$. For example, the surfactant $\mathrm{FC}_{4}$ can be used as a soft template to encapsulate lipase in mesoporous silica YSNs or attach resins to cores to produce mesoporous carbon shells $[49,53]$. The difficulties associated with the soft-templating method are problems in controlling the product uniformity and choosing appropriate surfactants [3,15].

Hard-templating methods perform well in the fabrication of rigid YSNs. Silica is a common hard template and is widely used to create noble metal@metal oxide YSNs. Hard templating is easily controlled, and the results are easy to predict and highly reproducible [48]. However, this synthetic method is not as popular as the soft-templating method used in industry because the range of particle shapes that can be obtained is limited and it is expensive, which makes it unsuitable for large-scale production. For example, mesoporous carbon nanoparticle synthesis using mesoporous silica as a hard template is not a feasible option, and soft templating is used instead [49]. However, hard-templating methods can be used for small-scale preparation of nanoparticles such as metal cores encapsulated in $\mathrm{TiO}_{2}$ shells $[54,55]$ and multishell $\mathrm{Au} / \mathrm{CeO}_{2}$ hollow spheres [48]. Soft- and hard-templating methods have so far only been used for producing spherical nanoparticles.

Ship-in-a-bottle methods can be used to create YSNs with a single core, multiple cores, or multiple shells and can be used for most types of material. As previously mentioned, the ship-in-a-bottle method is the reverse of other general synthetic approaches. It is therefore useful for producing highly inert materials which are difficult to dissolve and remove, such as zeolites [56]. The ship-in-a-bottle route is therefore an efficient, economical, and controllable method for synthesizing yolk-shell-nanostructured nanoparticles [22]; for example, the fabrication of yolk-shell HPW@hollow silicalite-1 has been reported [57].

Ostwald ripening is a template-free synthetic strategy and is a well-known method for generating nanoparticles with com-

Table 1

Comparison of common methods for YSNs synthesis.

\begin{tabular}{|c|c|c|c|c|c|}
\hline Synthesis method & Suitable composites & Nanoparticle structure & Complexity & Disadvantages & Ref. \\
\hline Selective etching & Most types of materials & Spherical and non-spherical & Moderate & Amount of etchant used & {$[3,35]$} \\
\hline Soft templating & Inorganic materials & Spherical & Simple & Uniformity; appropriate surfactants & {$[3,15,29]$} \\
\hline Hard templating & Metals and metal oxides & Spherical & Simple & Rigid shape particles only; costly & {$[15,29,48,49]$} \\
\hline Ship-in-bottle & Most types of materials & Spherical & Moderate & Shell needs to be prepared first. & {$[3,22]$} \\
\hline Ostwald ripening & $\begin{array}{l}\text { Inorganic oxides or sulphide } \\
\text { semiconducting materials }\end{array}$ & Complex & Moderate & Controlling of void space & {$[3,42]$} \\
\hline Galvanic replacement & Noble metals and metal oxides & Various shapes and structures & Moderate & $\begin{array}{c}\text { Time consuming; breakup of } \\
\text { nanostructure }\end{array}$ & {$[3,44,46,50]$} \\
\hline Kirkendall effect & Metals and alloys & Complex & Moderate & Untuneable & {$[3,37,44]$} \\
\hline
\end{tabular}


plex structures. This method is widely used to fabricate YSNs in inorganic oxide or sulfide semiconducting materials, e.g. $\mathrm{TiO}_{2}$-YSNs [58], Pt@CeO2 core-shell nanoparticles or YSNs [59], $\mathrm{Au} @ \mathrm{SiO}_{2}$ [39], and $\mathrm{ZnS}$ core-shell nanoparticles [60]. As mentioned above, Ostwald ripening is a spontaneous process, and although the void size can be controlled by varying the hydrothermal reaction time, precise tuning of the void size is still a major challenge in this fabrication process.

Galvanic replacement is used for metal and metal oxide YSN fabrication. $\mathrm{Au}, \mathrm{Pt}$, and $\mathrm{Pd}$ salts are the most common noble metal compounds, and $\mathrm{Ag}, \mathrm{Ni}, \mathrm{Al}$, and $\mathrm{Cu}$ are used as sacrificial templates in galvanic replacement processes [44,61]. The greatest advantage of this fabrication method is the ability to control the nanoparticle size and shape, and it is one of the most versatile synthetic methods for creating metal nanoparticles with complex structures. Morphological control greatly depends on the shapes and sizes of the template nanoparticles and the reaction conditions. In addition, chemicals such as $\mathrm{HCl}$ can be added to the solution to regulate the reaction kinetics to increase the morphological control [44]. However, this strategy also has drawbacks such as long reaction times and breakage of the nanostructure by dealloying, which tends to occur in the final stage of fabrication when the less noble metal redissolves from the shell material [44].

Kirkendall diffusion has attracted significant attention because of its frequent occurrence and the possibility of obtaining nanoparticles with unique compositions and complex structures [44]. Similarly to the galvanic replacement method, this synthetic method is suitable for metal and alloy materials, and the formation process is thermodynamically favourable [37]. The use of this method for fabricating YSNs is not yet well understood. It is believed that the yolk/core is initially connected to the shell by many filaments, as shown in Fig. 2(F), and the filaments break before the yolk/core completely disappears through diffusion. Because of the uncertainty and uncontrollability of the Kirkendall diffusion process, tuning the YSN morphology is a challenge.

The use of YSNs is growing rapidly, and there is increasing demand for yolk-shell nanoreactors with more complex structures which can be precisely tuned. Much research is therefore being devoted to investigating new and more advanced methods for YSN synthesis. Here, we briefly introduce one newly developed synthetic route that has good potential for synthesizing multicomponent core-shell or yolk-shell colloidal hybrid nanoparticles. The seed-mediated growth method was first used to synthesize noble metal nanocrystals; it is based on the galvanic replacement and selective etching methods. The seed, i.e. the less noble metal salt, serves as a sacrificial template, which is replaced by ions of a more noble metal in the introduced solution. Seed-mediated growth, which is similar to galvanic replacement, takes advantage of the fact that the activation energy of the metal reduction reaction between a less noble metal and more noble metal is lower than that of nucleation of the seeds themselves [62]. In addition, because the spontaneous nucleation of seeds is less favourable, natural and uneven crystal growth can be successfully suppressed; this is also the reason for the controllability of the nanoparticle shape and size [62]. Recently, this synthetic route has been successfully used to fabricate noble metal YSNs such as Ag@h-SiO 2 YSNs [63], and the research focus has moved to synthesizing non-noble metal cores encapsulated in porous silica shells, e.g. $\mathrm{Ni@SiO} \mathrm{YSN}_{2}$ [64]. Ni, which is one of the most effective catalysts, gives good catalytic performances in many significant reactions. The growth of non-noble metals is much more difficult to restrict than is seed growth of noble metals. This problem can be overcome by using a more powerful seed to restrict Ni growth within the porous shell. As shown in Fig. 3, Pd was used as an effective catalyst for decomposition of $\mathrm{Ni}^{2+}$-hydrazine complex [64]. $\mathrm{Pd}^{2+}$ ions were introduced onto $\mathrm{Fe}_{3} \mathrm{O}_{4}$ together with $\mathrm{Au}$ to form a stronger seed. After creation of the $\mathrm{Au}$ and $\mathrm{Pd}$ seed, $\mathrm{Ni}^{2+}-\left(\mathrm{N}_{2} \mathrm{H}_{4}\right)_{n}$ was added as a reducing agent and $\mathrm{Au}$ and $\mathrm{Pd}$ were replaced by $\mathrm{Ni}$ to form $\mathrm{Ni@SiO} 2$ YSNs.

\section{Advanced YSNs for energy-conversion applications}

Rapid advances in nanotechnology have led the chemical industry to a new peak. There have been enormous changes and improvements in the quality and quantity of chemical production compared with two decades ago. People therefore ask "What is the next move?" Of course, the next move will always be process optimization. Chemical processes involving renewable energy or low energy consumption, which have the potential to solve resource or environmental problems, always catch the world's attention. Catalysis of chemical reactions has become a key element in research.

The use of YSNs as nanoreactors for catalytic reactions has attracted much interest and become one of the hottest research topics. YSNs definitely have greater potential for use in long-lasting and low-cost catalytic processes than metal nanoparticles and core-shell nanoparticles, which also overcome many of the severe drawbacks of traditional catalysts. First, functionalization of both the core and the shell of YSNs can be achieved by attaching functional groups to the core and shell or by fabricating the core and shell from appropriate materials. Because of the differences between the physical and chemical properties of the yolk and shell, multiple catalytic reactions can be performed simultaneously. Second, the encapsulated core or cores with active sites can move freely inside the shell, which allows reactants to reach the active sites more easily, and this improves the catalytic activity. Next, the voids between the yolk and shell provide a homogeneous reaction environment for reactants, which minimizes environmental effects in catalytic reactions. It is well known that homogeneous catalysis gives better results than heterogeneous catalysis [65]. YSNs with various shapes, sizes, and structures can be easily produced

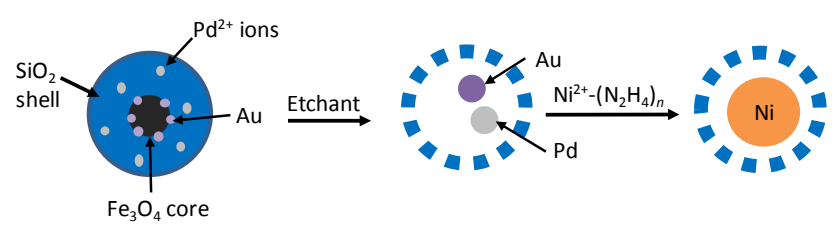

Fig. 3. Synthesis of $\mathrm{Ni@SiO} 2$ by seed-mediated growth. 
using the numerous excellent synthetic methods described in the synthesis section. The shapes, sizes, and structures are important factors in the catalytic performance; this is why a large amount of research has been devoted to the development of synthetic methods. There is no "one size fits all" case in catalysis; therefore the fabrication of catalysts with the most appropriate features for achieving the best performances is crucial. Finally, the most important function of yolk-shell nanostructures is to avoid aggregation and deactivation of the active cores. Dispersed nano active cores, especially pure metal cores, tend to aggregate and lose their catalytic activity during exposure to chemicals, products, or by-products under experimental conditions. The YSN shell therefore acts as a protecting layer that efficiently prevents damage and allows transport of reactants and products from active sites.

Because of the many advantages of YSNs as catalysts for chemical reactions, any research conducted on this topic could lead to a scientific breakthrough. In the following subsections, we summarize a few important and advanced yolk-shell catalyst applications such as methane reforming, photocatalysis, and electrocatalysis. These reactions play significant roles in the current chemical industry and contribute greatly to green energy and chemical production.

\subsection{Use of carbon sources - methane reforming}

Clean and efficient energy generation is much needed because of our current environmental situation. Conversion of one of the major greenhouse gases, namely methane, to clean syngas/ $\mathrm{H}_{2}$ gas is a significant development in sustainable energy generation. $\mathrm{H}_{2}$ gas combustion is another important method for producing energy, and $\mathrm{H}_{2}$ is also an important chemical in petroleum refining. A number of $\mathrm{H}_{2}$ production processes are available, such as steam reforming of methane (SRM), $\mathrm{CO}_{2}$ (dry) reforming of methane (DRM), partial oxidation of methane (POM), bi-reforming of methane, autothermal reforming of methane, and tri-reforming of methane [66]. Among these, SRM, DRM, and POM are more commonly used. $\mathrm{H}_{2}$ production from natural sources is a good starting point for decreasing or even eliminating the use of traditional fuels such as diesel and coke. Ni has always been the most popular metal catalyst for methane reforming reactions. $\mathrm{Rh}, \mathrm{Ru}$, and $\mathrm{Pt}$ are also effective catalysts, but they are rare and expensive [67-69]. Because of their availability, ease of preparation, and low cost, $\mathrm{Ni}$ and Co are the favoured catalysts in the methane reforming industry [67,69-71]. Ni nanoparticles are air sensitive and are deactivated during methane reforming because of carbon deposition on the catalyst surface over a period of time [66,69,70,72-74]. Core-shell and yolk-shell-nanostructured catalysts have therefore been used in methane reforming reactions to prevent carbon deposition on metal nanoparticles and agglomeration. It is believed that the protecting shell efficiently blocks carbon deposition on the edges and corners of active metal nanoparticles [75]. Here, we briefly introduce some core-shell-structured catalysts, concentrating on YSNs, which have been used in SRM, DRM, and POM $\mathrm{H}_{2}$ production processes.
SRM is the most important and well-developed $\mathrm{H}_{2}$ production method, and it currently accounts for the largest proportion of total $\mathrm{H}_{2}$ gas production $[66,76]$. Syngas (a mixture of $\mathrm{CO}$ and $\mathrm{H}_{2}$ gas) is the product of SRM [Eq. 1(1)], and the water-gas shift reaction [Eq. 1(2)] increases the yield of $\mathrm{H}_{2}$ gas in the final product. SRM is a highly endothermic chemical process, which requires a large energy input for operation between 675 and $1000{ }^{\circ} \mathrm{C}$ and high-pressure conditions. This environment makes many materials unsuitable as supports for active metal catalysts $[66,70,76]$. Moreover, to prevent carbon deposition, which deactivates metal catalysts, the water/methane ratio of the input reactants should be high (over 1:1); this is also required for the water-gas shift reaction $[66,70,74]$.

Eq. 1: (1) SRM reaction equation; (2) water-gas shift reaction equation

$$
\begin{array}{lr}
\mathrm{CH}_{4}+\mathrm{H}_{2} \mathrm{O} \rightarrow \mathrm{CO}+3 \mathrm{H}_{2} & \Delta H_{298^{\circ}}=+206 \mathrm{~kJ} / \mathrm{mol} \\
\mathrm{CO}+\mathrm{H}_{2} \mathrm{O} \rightarrow \mathrm{CO}_{2}+\mathrm{H}_{2} & \Delta H_{298^{\circ}}=-41 \mathrm{~kJ} / \mathrm{mol}
\end{array}
$$

Core-shell nanoparticles were first used in the SRM before YSNs were used. $\mathrm{Ni}_{\text {core }} @ \mathrm{SiO}_{2}$ (11 wt\% Ni), which was synthesized using a deposition-precipitation method, achieved an approximate methane conversion of $85 \%$ at $750{ }^{\circ} \mathrm{C}$, with an inlet water/methane ratio of 3:1, in the first $4 \mathrm{~h}$ [66]. Core-shell nanoparticles consisting of a $\mathrm{Ni}$ core and $\mathrm{Al}_{2} \mathrm{O}_{3}$ shell, i.e. $\mathrm{Ni}_{\text {core }} @ \mathrm{Al}_{2} \mathrm{O}_{3}$ (10 wt\% Ni), were prepared under multibubble sonoluminescence conditions, and gave $97 \%$ methane conversion at $750{ }^{\circ} \mathrm{C}$ at a water/methane ratio of 2 for reaction times up to $5 \mathrm{~h}[74]$.

In further modifications of the catalysts, yolk-shell-structured $\mathrm{Ni@SiO} 2$ catalysts were prepared by directly coating a $\mathrm{Ni}$ core with a silica shell, followed by selective etching of the core, and porous shell formation by calcination [72]. SRM was performed using $\mathrm{Ni@SiO} 2$ (89 wt\% Ni) as a catalyst in a fixed-bed continuous-flow reactor at atmospheric pressure and $700{ }^{\circ} \mathrm{C}$. A high water/methane ratio was used in the inlet to minimize the possibility of carbon deposition. The methane conversion and $\mathrm{H}_{2}$ concentration were high, above $90 \%$ and $70 \%$, respectively, for a reaction period up to $4 \mathrm{~h}$. The experimental results were close to the theoretical values, and the catalytic activity of the recycled catalyst was almost the same as that of the fresh catalyst [72]. Steam reforming experiments were also performed using yolk-shell catalysts with various metal weight percentages under the same experimental conditions. The metal weight percentage in the catalyst did not greatly affect the methane conversion or $\mathrm{H}_{2}$ concentration. For example, with 20 wt $\% \mathrm{Ni}$ in the catalyst, the methane conversion and $\mathrm{H}_{2}$ concentration were $85 \%$ and $70 \%$, respectively [72].

A Ni@ZrO 2 yolk-shell catalyst was synthesized using a double-template emulsion method by coating silica and $\mathrm{ZrO}_{2}$ shells sequentially on Ni nanoparticles, followed by silica etching to form a yolk-shell structure [70]. Very small Ni cores were synthesized using a reverse micelle approach, which is believed to facilitate particle dispersion, increase the number of active catalytic sites, and prevent coke formation [70]. The catalytic

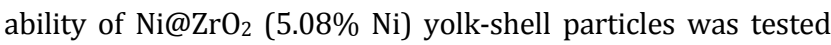
using a fixed-bed quartz reactor at $750{ }^{\circ} \mathrm{C}$, atmospheric pressure, and a steam/methane input ratio of 2.5. The results showed high catalytic activity, giving 93\% methane conversion, 
and the activity was retained for $150 \mathrm{~h}$, as shown in Fig. 4.

The catalytic performances of the core-shell and yolk-shell nanoreactors mentioned above in SRM were compared. The

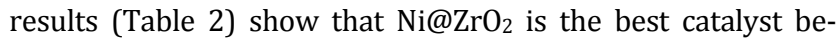
cause it gives good methane conversion, has a low metal weight percentage, good stability and recyclability, and is easily synthesized.

DRM is an important process because it converts two major greenhouse gases (methane and $\mathrm{CO}_{2}$ ) to a useful product, i.e. syngas, as shown in Eq. 2. Similar to SRM, DRM is also a highly endothermic reaction, which requires a high operating temperature. Initially, DRM was not investigated as intensively as SRM because of its low $\mathrm{H}_{2} / \mathrm{CO}$ ratio (1/1); a low $\mathrm{H}_{2}$ gas ratio in the final product is undesirable and coke formation becomes problematic in the absence of steam [77]. However, this product ratio is appropriate for producing synthetic fuel via Fisch-
er-Tropsch synthesis; therefore DRM has recently become a popular research topic $[69,77,78]$.

Eq. 2: DRM reaction equation

$\mathrm{CH}_{4}+\mathrm{CO}_{2} \rightarrow 2 \mathrm{CO}+2 \mathrm{H}_{2} \quad \Delta H_{298^{\circ}}=+247 \mathrm{~kJ} / \mathrm{mol}$

$\mathrm{Ni}_{\text {core }} @ \mathrm{Al}_{2} \mathrm{O}_{3}$ core-shell nanoparticles also gave excellent performances in DRM, giving $92 \%$ methane conversion and $95 \% \mathrm{CO}_{2}$ conversion at $800{ }^{\circ} \mathrm{C}$ for up to $150 \mathrm{~h}$, with a $\mathrm{CH}_{4} / \mathrm{CO}_{2}$ input ratio of 1 . $\mathrm{Ni}_{\text {core }} @ \mathrm{MgO}-\mathrm{Al}_{2} \mathrm{O}_{3}$ core-shell nanoparticles gave similar catalytic result under the same test conditions [79].

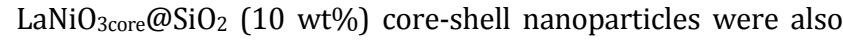
tested in DRM in a coaxial dielectric barrier discharge plasma reactor under ambient conditions. The catalytic performance was better than that of traditional $\mathrm{Ni}_{\text {core }} @ \mathrm{SiO}_{2}$, with $\mathrm{CH}_{4}$ and $\mathrm{CO}_{2}$ conversions of $88 \%$ and $78 \%$, respectively [78]. As well as conventional spherical nanoparticles, $\mathrm{Ni}-\mathrm{Mg}$ phyllosilicate nanotubes@silica (Ni-Mg PSNTS@SiO 2 ) core-shell nanoreac-

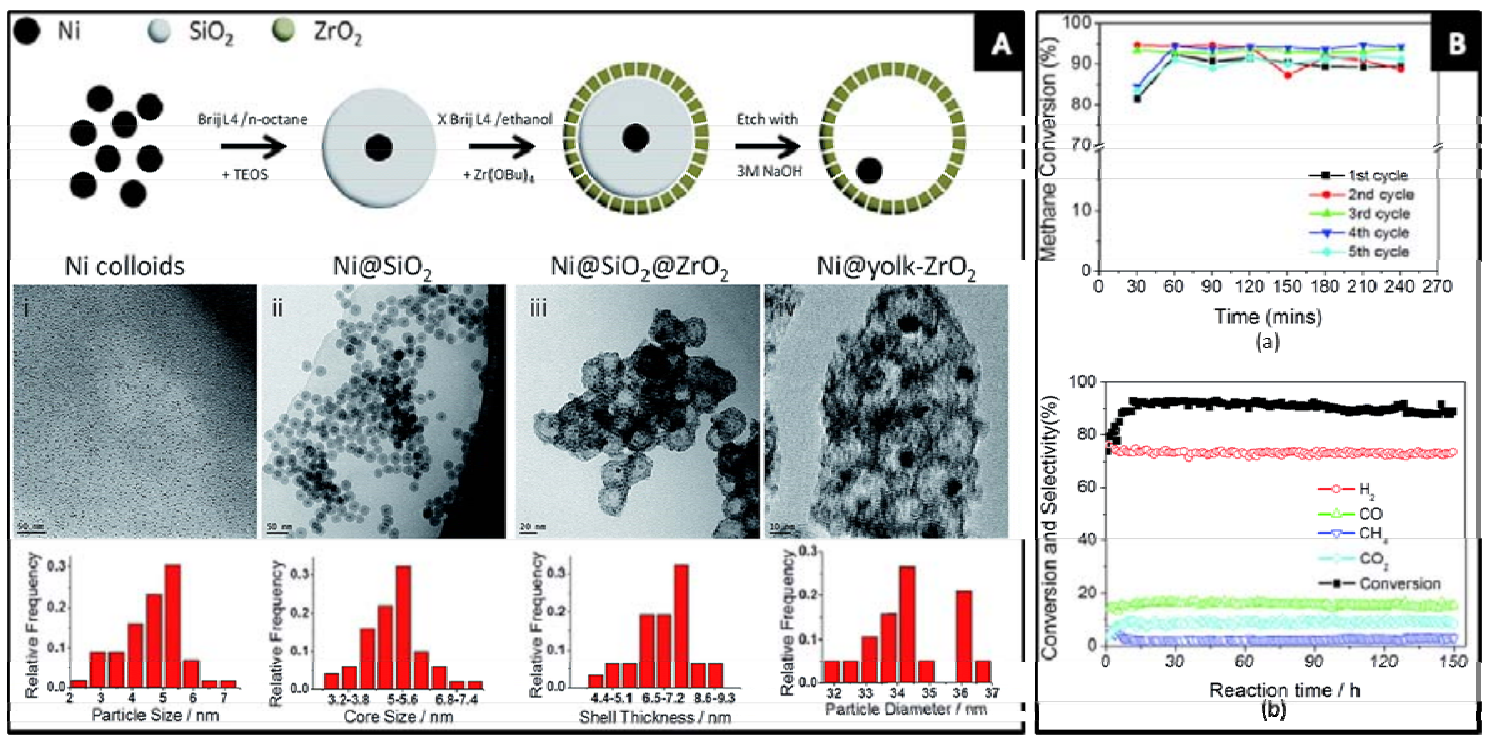

Fig. 4. (A) Schematic diagram of synthesis of $\mathrm{Ni}_{\mathrm{Z}} \mathrm{ZrO}_{2}$ YSNs, and transition electron microscopy images and core-size distributions at each synthetic

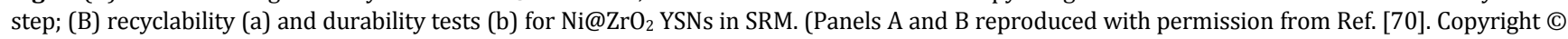
The Royal Society of Chemistry 2015.)

Table 2

Summary of catalytic performances of nanoreactors used in SRM, DRM, and POM.

\begin{tabular}{|c|c|c|c|c|c|c|c|}
\hline \multirow{2}{*}{ Application } & \multicolumn{3}{|c|}{ Catalyst } & \multicolumn{3}{|c|}{ Performance } & \multirow{2}{*}{ Ref. } \\
\hline & Particle name & Structure* & $\mathrm{Ni}(\mathrm{wt} \%)$ & Operating temperature $(\mathrm{K})$ & $\mathrm{CH}_{4}$ conversion $(\%)$ & Tested durability (h) & \\
\hline \multirow{4}{*}{ SRM } & $\mathrm{Ni}_{\text {core }} @ \mathrm{SiO}_{2}$ & CS & 11 & 1023 & 85 & 4 & [66] \\
\hline & $\mathrm{Ni}_{\text {core }} @ \mathrm{Al}_{2} \mathrm{O}_{3}$ & CS & 10 & 1023 & 97 & 5 & [74] \\
\hline & $\mathrm{Ni} @ \mathrm{SiO}_{2}$ & YS & 89 & 973 & 90 & 4 & [72] \\
\hline & $\mathrm{Ni@ZrO} 2$ & YS & 5.08 & 1023 & 93 & 150 & [70] \\
\hline \multirow{6}{*}{ DRM } & $\mathrm{Ni}_{\text {core }} @ \mathrm{Al}_{2} \mathrm{O}_{3}$ & CS & 11 & 1073 & 92 & 150 & [79] \\
\hline & 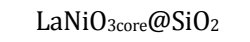 & CS & 10 & NA & 88.3 & 30 & [78] \\
\hline & Ni-Mg PSNTS@SiO 2 & CS & 11.6 & 1023 & 85 & 72 & [71] \\
\hline & Ni-yolk@Ni@SiO2 & YS & 18.6 & 1073 & 90 & 90 & [80] \\
\hline & $\mathrm{Ni} @ \mathrm{SiO}_{2}$ & YS & 42.4 & 973 & 43.9 & 590 & [81] \\
\hline & $\mathrm{NiCe} @ \mathrm{~m}-\mathrm{SiO}_{2}$ & YS & 10.6 & 1023 & 95.2 & 40 & [69] \\
\hline \multirow{4}{*}{ POM } & $\mathrm{Ni}_{\text {corere}} @ \mathrm{Al}_{2} \mathrm{O}_{3}$ & CS & 10 & 1073 & 96 & 50 & [83] \\
\hline & Ni-350@meso-SiO 2 & CS & 43 (calculated) & 1023 & 93 & 8.3 & [73] \\
\hline & 0.1La-Ni@SiO 2 & CS & 43 (calculated) & $\begin{array}{r}973 \\
1023\end{array}$ & $\begin{array}{l}85.2 \\
96.1\end{array}$ & 64 & [84] \\
\hline & $\mathrm{Ni} / \mathrm{ZrO}_{2} @ \mathrm{SiO}_{2}$ & CS & 24.8 & 1023 & 99 & 160 & {$[75]$} \\
\hline
\end{tabular}

*CS: Core-shell; YS: Yolk-shell. 
tors were recently synthesized, and gave $85 \% \mathrm{CH}_{4}$ conversion and $89 \% \mathrm{CO}_{2}$ conversion at $750{ }^{\circ} \mathrm{C}$; the nanoparticles were stable for $72 \mathrm{~h}$ [71].

Yolk-shell catalysts with a yolk-satellite-shell structure (Fig. $1(\mathrm{C})$ ), i.e. Ni-yolk@Ni@SiO 2 nanoparticles, have been synthesized by selective etching via calcination and reduction [80]. These nanoparticles consisting of a Ni yolk and satellite encapsulated within a silica shell had high stabilities and catalytic activities in $\mathrm{CO}_{2}$ (dry) reforming of methane; the performances of Ni-yolk@Ni@SiO 2 were highly dependent on the silica shell thickness [80]. When the silica shell thickness was $11.2 \mathrm{~nm}$ or more, the core-shell $\mathrm{Ni@SiO} 2$ structure was converted to a yolk-satellite-shell nanocomposite, i.e. Ni-yolk@Ni@SiO 2 , by calcination at $800{ }^{\circ} \mathrm{C}$ for $2 \mathrm{~h}$ [80]. A series of experiments were performed using $\mathrm{Ni}$-yolk@Ni@SiO 2 nanoreactors with various shell thicknesses as catalysts in DRM. The results show that the nanoreactor catalytic activity, stability, and carbon resistance increased with increasing shell thickness, and that small $\mathrm{Ni}$ satellites around the Ni core improved the catalytic activity. At the optimum shell thickness, i.e.11.2 nm, Ni-yolk@Ni@SiO gave $90 \% \mathrm{CH}_{4}$ conversion and $95 \% \mathrm{CO}_{2}$ conversion for up to 90 $\mathrm{h}$ without any carbon deposition.

$\mathrm{Ni@SiO} 2$ yolk-shell nanoreactors, which were fabricated using the synthetic method reported by Song and his colleagues [72] (summarized in the discussion of SRM), were also tested in

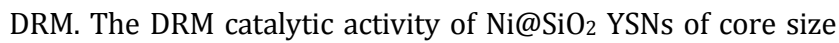
approximately $46.4 \mathrm{~nm}$ was low compared with their high activity in SRM. Because of the reverse waster-gas shift reaction, the $\mathrm{CH}_{4}$ conversion (43.9\%) was lower than the $\mathrm{CO}_{2}$ conversion
$(57.3 \%)$ at $700{ }^{\circ} \mathrm{C}$; it is suggested that water supplied by the reaction helps to stabilize the catalyst and prevent carbon deposition [81]. However, despite the catalytic activity, $\mathrm{Ni@SiO} 2$ showed excellent durability up to $590 \mathrm{~h}$ at both 700 and $800{ }^{\circ} \mathrm{C}$ and the conversions of $\mathrm{CH}_{4}$ and $\mathrm{CO}_{2}$ increased with increasing operating temperature because the DRM is endothermic, but the gas hourly space velocity of the reactants was unchanged [81].

Bimetallic mesoporous shell NiCe@m-SiO 2 yolk-shell catalysts synthesized by encapsulating $\mathrm{CeO}_{2}$ - modified $\mathrm{Ni}$ nanoparticles (less than $10 \mathrm{wt} \% \mathrm{Ce}$ ), formed in situ, in mesoporous silica shells significantly improved the dispersion of Ni nanoparticles, catalytic performance, and suppression of coke formation [69]. DRM was performed in a fixed-bed reactor with a quartz tube and a reactant input ratio of 1:1. The $\mathrm{CH}_{4}$ conversion reached $97.6 \%$ at $800{ }^{\circ} \mathrm{C}$ and $95.2 \%$ at $750{ }^{\circ} \mathrm{C}$, and the conversion was unchanged after $40 \mathrm{~h}$, as shown in Fig. 5 [69]. In $\mathrm{DRM}, \mathrm{CH}_{4}$ conversion is lower than $\mathrm{CO}_{2}$ conversion because of the reverse water-gas shift reaction, and the catalytic performance increases with increasing reaction temperature. Table 2 summarizes the performances of the core-shell and yolk-shell catalysts used in DRM. Current research on DRM is progressing rapidly, and it is believed that more efficient and well-designed nanoreactors will be available in the near future.

POM, also called oxy-methane reforming, mainly produces syngas $\left(\mathrm{H}_{2}+\mathrm{CO}\right)$. POM has some advantages over traditional SRM and DRM. POM produces syngas, which is desirable in green energy production, with a $\mathrm{H}_{2} / \mathrm{CO}$ ratio of 2 , and the reaction $\left(\mathrm{CH}_{4}+1 / 2 \mathrm{CO}_{2} \rightarrow \mathrm{CO}+2 \mathrm{H}_{2}: \Delta H_{298^{\circ}}=-37 \mathrm{~kJ} / \mathrm{mol}\right)$ is slightly

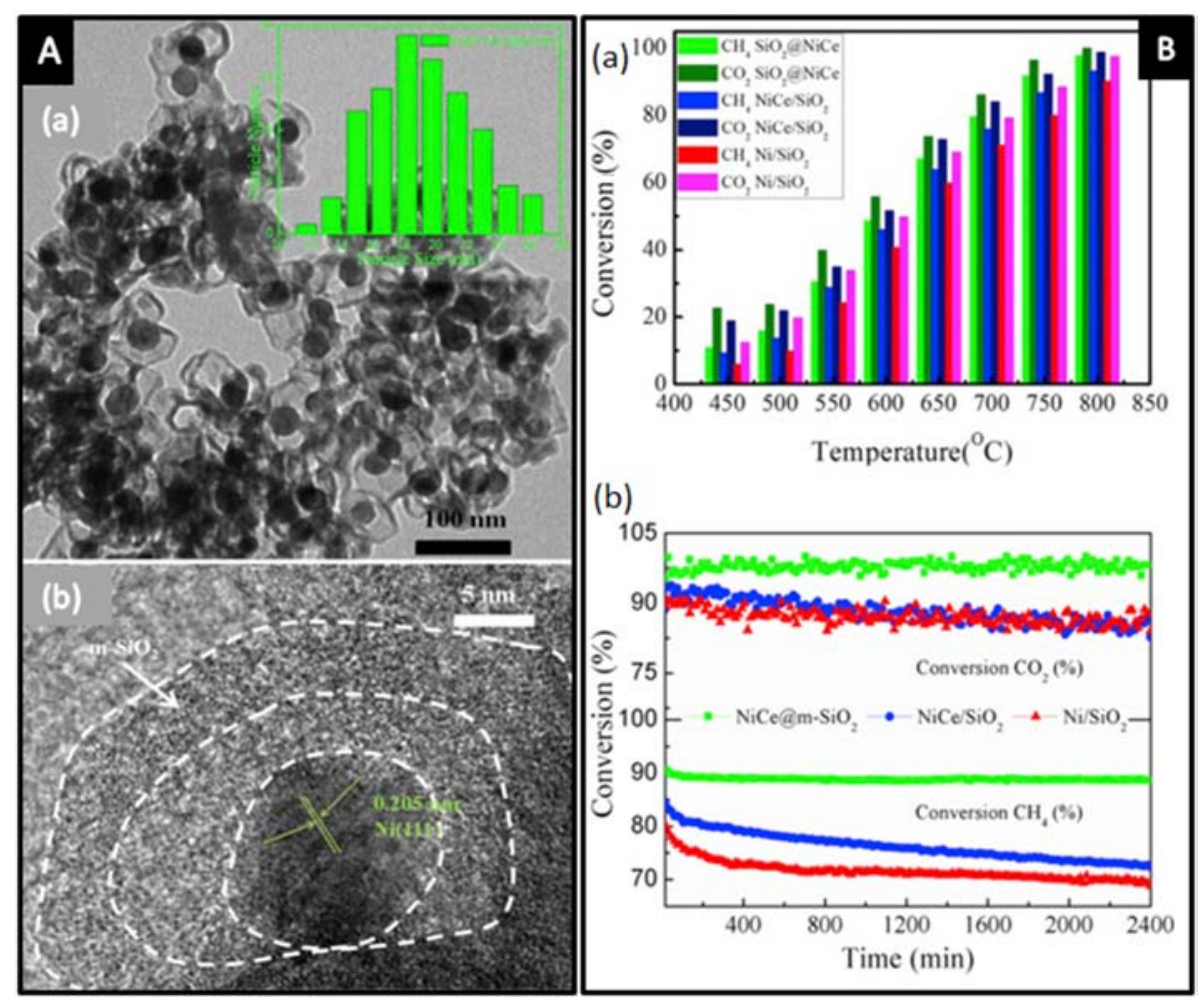

Fig. 5. (A) Transition electron microscopy (TEM) image of $\mathrm{NiCe@m-SiO} \mathrm{Y}_{2} \mathrm{YSN}$ and (inset) size distribution of Ni nanoparticles (a); and high-resolution TEM image of $\mathrm{NiCe} @ \mathrm{~m}-\mathrm{SiO}_{2}$ YSNs (b); (B) $\mathrm{CH}_{4}$ and $\mathrm{CO}_{2}$ conversions over different catalysts at various temperatures (a) and catalytic stabilities of different catalysts (b). (Panels A and B reproduced with permission from Ref. [69]. Copyright (c 2015, Hydrogen Energy Publications.) 
exothermic and therefore needs less energy. The operating costs for POM are therefore lower than those for SRM and DRM $[73,82]$. The first catalysts developed for POM, consisting of $\mathrm{Ni}$ metal on an $\mathrm{Al}_{2} \mathrm{O}_{3}$ support, gave very high methane conversions and syngas selectivities, but severe sintering and aggregation of the catalysts occurred during the reaction [73]. Nanoparticles consisting of a Ni core encapsulated in an $\mathrm{Al}_{2} \mathrm{O}_{3}$ shell were synthesized. $\mathrm{Ni}_{\text {core }} @ \mathrm{Al}_{2} \mathrm{O}_{3}$ (10 wt\%) core-shell nanoparticles gave an excellent catalytic performance in POM, with a methane conversion of $96 \%$ [83]. Nanoparticles consisting of a Ni core encapsulated in a porous silica shell were also tested in POM. This nanocomposite has a high activity and long lifetime, especially at high temperatures. A Ni-350@meso-SiO 2 core-shell catalyst prepared using a modified Stöber method gave a maximum methane conversion of approximately $93 \%$ with $92 \%$ CO selectivity and $87 \% \mathrm{H}_{2}$ selectivity [73]. The catalytic performance was tested in a continuous-flow fixed-bed reactor at atmospheric pressure and $750{ }^{\circ} \mathrm{C}$ for $500 \mathrm{~min}$. The results show that the selectivity for $\mathrm{H}_{2}$ was only slightly lower than that for CO. The catalytic activity was highly dependent on the size of the Ni core and an increase in the core size resulted in a significant decrease in methane conversion and selectivities for $\mathrm{CO}$ and $\mathrm{H}_{2}$ [73]. The same research team doped $\mathrm{Ni} @ S i O_{2}$ core-shell nanoreactors with various metals. The results show

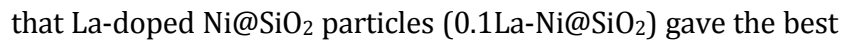
performance in terms of catalytic ability and durability by decreasing carbon deposition [84]. Recently, Ni/ZrO ${ }_{2} @ \mathrm{SiO}_{2}$ (24.8 $w \mathrm{t} \% \mathrm{Ni}, \mathrm{Ni} / \mathrm{Zr}=1$ ) core-shell nanoparticles synthesized using a modified Stöber method were tested in POM. A methane conversion of $99 \%$ was achieved at $750{ }^{\circ} \mathrm{C}$ [75]. To the best of our knowledge, no yolk-shell-structured catalysts have been used in in POM. The catalytic performances of all the core-shell catalysts discussed are listed in Table 2.

\subsection{Photocatalysis}

Photocatalysis can be defined as the acceleration of chemical reactions by light energy. It has been widely researched for decades because it is a green process. Photocatalytic reactions can be classified as up-hill or down-hill; up-hill reactions convert light to chemical energy, e.g. photosynthesis in plants, whereas down-hill reactions convert reactants to products via light absorption [85]. Artificial up-hill reactions are currently of great interest. Photocatalysis is attractive and important in many applications such as organic pollutant degradation, selective organic transformations, killing cancer cells, water splitting, reduction of $\mathrm{CO}_{2}$, and biomass conversion [59,86]. Among these applications, research is currently focused on water splitting, reduction of $\mathrm{CO}_{2}$, and organic pollutant degradation. As mentioned in the section on methane reforming, there is a great demand for sustainable energy production. Photocatalysis can make an important contribution to green energy generation; it has the advantages of eliminating harsh reaction conditions and increasing reaction rates via visible-light absorption $[59,87]$. Abundant data are available because photocatalysis has been extensively researched for many decades. Here, we summarize current progress in research on core-shell materials and YSNs as catalysts for water splitting, reduction of $\mathrm{CO}_{2}$, and organic pollutant degradation; the catalytic performances of all the nanoreactors discussed are listed in Table 3.

Water splitting, which converts water to clean fuels, i.e. $\mathrm{H}_{2}$ and $\mathrm{O}_{2}$, using solar energy, is the most attractive photocatalytic

Table 3

Summary of catalytic performances of nanoreactors used in photocatalytic water splitting, $\mathrm{CO}_{2}$ reduction, and pollutant degradation.

\begin{tabular}{|c|c|c|c|c|c|c|c|}
\hline \multirow[b]{2}{*}{ Application } & \multicolumn{2}{|l|}{ Catalyst } & \multicolumn{4}{|c|}{ Performance } & \multirow[b]{2}{*}{ Ref. } \\
\hline & Particle name & Structure* & Illumination & $\begin{array}{c}\mathrm{H}_{2} \text { production } \\
\left(\mu \mathrm{mol} \mathrm{h} \mathrm{h}^{-1} \mathrm{~g}^{-1}\right)\end{array}$ & $\begin{array}{l}\text { Quantum } \\
\text { efficiency }\end{array}$ & $\begin{array}{c}\text { Tested time } \\
(\mathrm{h})\end{array}$ & \\
\hline Water splitting & $\mathrm{NiFe}_{2} \mathrm{O}_{4} @ \mathrm{TiO}_{2}$ & $\mathrm{CS}$ & UV-vis light $(\lambda=365 \mathrm{~nm})$ & 215.8 (calculated) & NA & 8 & [89] \\
\hline $2 \mathrm{H}_{2} \mathrm{O} \leftrightarrow$ & $\mathrm{Pt}-\mathrm{SiO}_{2} @ \mathrm{IrO}_{2}-\mathrm{Ti}_{3} \mathrm{~N}_{5}$ & $\mathrm{CS}$ & $U V$-vis light $(\lambda>420 \mathrm{~nm})$ & 46 (calculated) & NA & NA & [92] \\
\hline \multirow[t]{4}{*}{$2 \mathrm{H}_{2}+\mathrm{O}_{2}$} & $\mathrm{SrTiO}_{3}$ core: $\mathrm{La} / \mathrm{Rh}$ & $\mathrm{CS}$ & UV-vis light $(\lambda>420 \mathrm{~nm})$ & 280 (calculated) & NA & 16 & [95] \\
\hline & h-(pt- $\left.\mathrm{TiO}_{2}\right) / \mathrm{CdS}$ & YS & Visible light $(\lambda>420 \mathrm{~nm})$ & 29600 & $14.5 \%$ & 70 & [87] \\
\hline & (Ni-ZnO)@C & YS & UV-vis light & 5.01 & NA & NA & [88] \\
\hline & $\mathrm{Au} @ \mathrm{r}-\mathrm{GO} / \mathrm{TiO}_{2}$ & YS & Visible light $(\lambda<400 \mathrm{~nm})$ & 462 & $2.5 \%$ & 24 & [98] \\
\hline \multirow[t]{6}{*}{$\begin{array}{l}\text { Carbon dioxide } \\
\text { reduction }\end{array}$} & Particle name & Structure* & Illumination & $\begin{array}{l}\text { Carbon fuel production } \\
\qquad\left(\mu \mathrm{mol} \mathrm{h}{ }^{-1} \mathrm{~g}^{-1}\right)\end{array}$ & Chemic & reaction & \\
\hline & $\mathrm{Au} @ \mathrm{TiO}_{2}$ & YS & UV-vis light & $\begin{aligned} \mathrm{CH}_{4} & =6.34 \\
\mathrm{C}_{2} \mathrm{H}_{4} & =0.68\end{aligned}$ & \multicolumn{2}{|c|}{$\mathrm{CO}_{2}+2 \mathrm{H}_{2} \mathrm{O} \rightarrow 2_{2}+\mathrm{CH}_{4}$} & {$[107]$} \\
\hline & $\mathrm{C} @ \mathrm{TiO}_{2}$ & YS & Solar light & $\mathrm{CH}_{4}=4.22$ & \multirow{2}{*}{\multicolumn{2}{|c|}{$2 \mathrm{CO}_{2}+2{ }_{2} \mathrm{O} \rightarrow 3 \mathrm{O}_{2}+\mathrm{C}_{2} \mathrm{H}_{4}$}} & [112] \\
\hline & 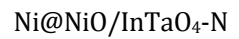 & $\mathrm{CS}$ & Visible light $(\lambda=390-770 \mathrm{~nm})$ & $\mathrm{CH}_{4} \approx 160$ (calculated) & & & {$[59,109]$} \\
\hline & $\mathrm{Cu} / \mathrm{Pt} / \mathrm{TiO}_{2}$ & $\mathrm{CS}$ & $U V$-vis light $(\lambda=320-780 \mathrm{~nm})$ & $\mathrm{CH}_{4}=3$ & \multicolumn{2}{|c|}{$2 \mathrm{CO}_{2}+3 \mathrm{H}_{2} \mathrm{O} \rightarrow 3.5 \mathrm{O}_{2}+\mathrm{C}_{2} \mathrm{H}_{6}$} & [108] \\
\hline & Ag-MWCNT@ $\mathrm{TiO}_{2}$ & $\mathrm{CS}$ & Visible light & $\begin{array}{r}\mathrm{CH}_{4}=6.34 \\
\mathrm{C}_{2} \mathrm{H}_{4}=0.68\end{array}$ & & & {$[110]$} \\
\hline $\begin{array}{l}\text { Degradation of } \\
\text { pollutants }\end{array}$ & Particle name & Structure* & Illumination & $\begin{array}{l}\text { Pollutant degradation } \\
\text { efficiency (\%) }\end{array}$ & $\begin{array}{l}\text { Quantum } \\
\text { efficiency }\end{array}$ & Tested time & \\
\hline $\mathrm{R}+\mathrm{OH}^{-} \rightarrow$ & $\mathrm{Au} @ \mathrm{r}-\mathrm{GO} / \mathrm{TiO}_{2}$ & YS & Visible light $(\lambda=400 \mathrm{~nm})$ & $\mathrm{RhB}=99$ & $3.4 \%$ & $100 \mathrm{~min}$ & [98] \\
\hline \multirow[t]{3}{*}{$\mathrm{R}^{-}+\mathrm{H}_{2} \mathrm{O}$} & $\mathrm{Fe}_{3} \mathrm{O}_{4} @ \mathrm{C} @ \mathrm{TiO}_{2}$ & YS & UV light & $\mathrm{RhB} \approx 99$ & NA & $90 \mathrm{~min}$ & [117] \\
\hline & ${\mathrm{C} @ \mathrm{TiO}_{2}}_{2}$ & YS & UV light $(\lambda=365 \mathrm{~nm})$ & $\mathrm{RhB} \approx 99$ & NA & $30 \mathrm{~min}$ & [118] \\
\hline & $\mathrm{Fe}_{3} \mathrm{O}_{4} @ \mathrm{TiO}_{2} @ \mathrm{Ag}$ & YS & UV and visible lights & $\begin{array}{c}\mathrm{AMP}=98.7 \text { (UV) } \\
\mathrm{AMP}=91.5 \text { (Visible) }\end{array}$ & NA & $360 \mathrm{~min}$ & [119] \\
\hline
\end{tabular}

*CS: Core-shell; YS: Yolk-shell. 
reaction. Traditionally, $\mathrm{H}_{2}$ has been obtained from seawater by chemical electrolysis. This method is not widely used for large-scale production of $\mathrm{H}_{2}$ because of the very high operating costs [88]. The use of photocatalysis could overcome this problem and enable the development of low-cost and efficient methods for $\mathrm{H}_{2}$ gas generation. In photocatalytic water splitting, electrons in conduction bands and holes in valence bands split water molecules into oxygen and hydrogen; the electrons and holes are created by ionization of photocatalysts through exposure to light (Fig. 6(A)) [89]. Since the 1970s, when Fujishima and Honda first reported the use of $\mathrm{TiO}_{2}$ as a catalyst for water splitting, much research has been conducted on developing appropriate photocatalytic systems for producing chemical energy through water splitting [85,90,91].

Many materials such as noble metals, metal oxide semiconductors, nitrides, oxynitrides, and oxysulfides have been investigated as potential catalysts [92,93]. Among all the tested photocatalysts, semiconductors are the most suitable because they have appropriate bandgaps, low electrical resistance, are cheap, and can be produced on a large scale [93]. A semiconductor of small particle size was first used for water splitting, but the particles recombined via the charges created by light absorption, causing a decrease in the surface area and efficiency [94]. Photocatalytic water splitting consists of two half reactions: water oxidation to $\mathrm{O}_{2}$ and water reduction to $\mathrm{H}_{2}[92,95]$; specific catalysts are needed for each half reaction. Advanced-structured and composite nanoreactors have been designed, synthesized, and tested for water splitting. Noble metal and transition metal oxides are often used as cocatalysts in nanoreactors with advanced structures [92,96]. These advanced nanoreactors increase the conversion rate and prevent recombination of the products $\left(\mathrm{H}_{2}\right.$ and $\left.\mathrm{O}_{2}\right)$ to water molecules. The performances of $\mathrm{TiO}_{2}$ and $\mathrm{ZnO}$ are better than those of other semiconductors $[88,90,93]$. $\mathrm{TiO}_{2}$ can only be excited by

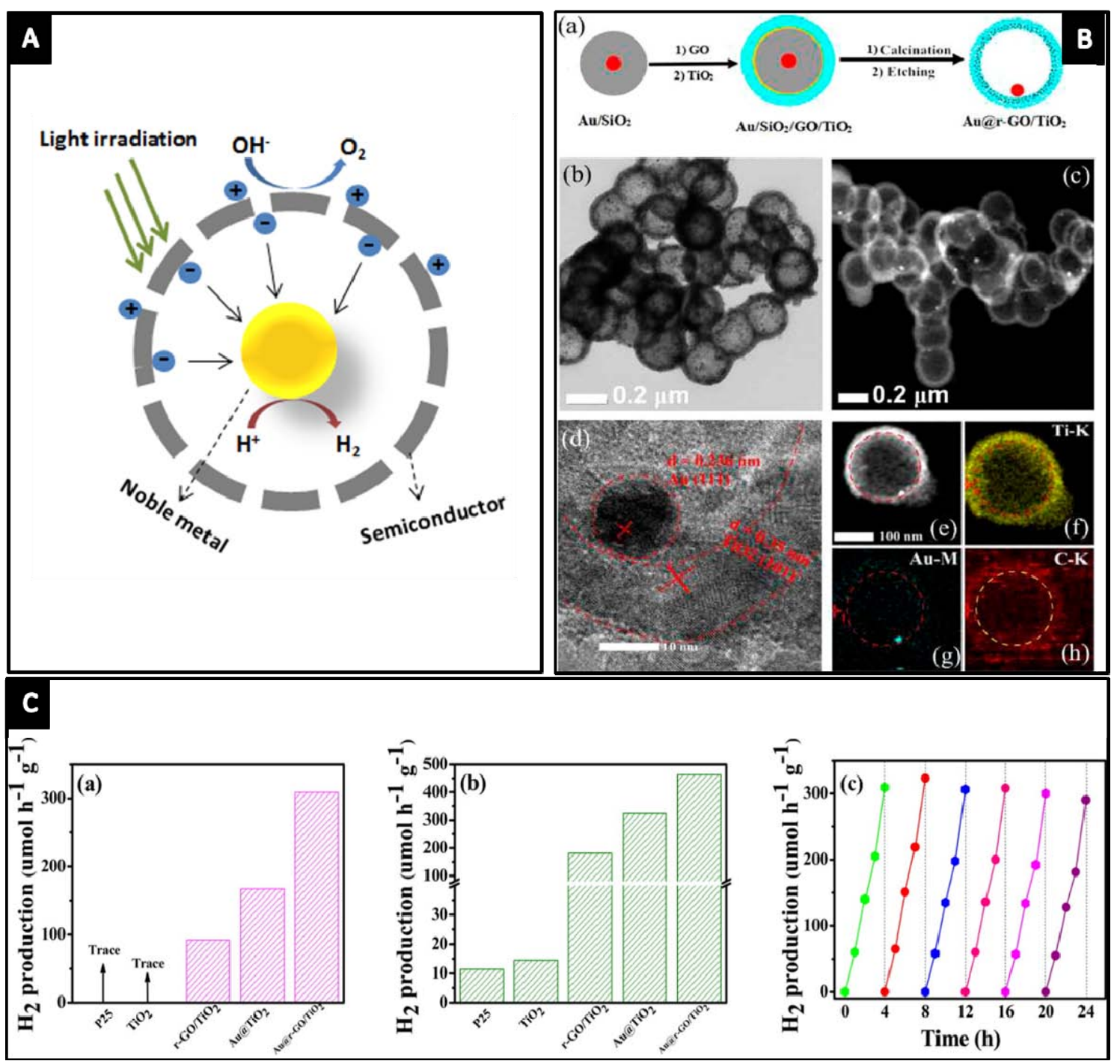

Fig. 6. (A) Schematic diagram of water splitting mechanism using noble metal@semiconductor $\mathrm{YSNs}$ (B) schematic diagram of $\mathrm{Au} @ \mathrm{r}-\mathrm{GO} / \mathrm{TiO} \mathrm{S}_{2} \mathrm{syn}-$ thetic steps (a), TEM image (b), and high-resolution TEM image (d) of Au@r-GO/TiO $\mathrm{O}_{2}$, high-angle angular dark-field-scanning TEM images of $\mathrm{Au} @ \mathrm{r}-\mathrm{GO} / \mathrm{TiO}_{2}$ (c, e), energy-dispersive X-ray spectroscopy mapping images of single Au@r-GO/TiO 2 nanoparticles (f-h); (C) comparison of $\mathrm{H}_{2}$ production from methanol aqueous solution using different catalysts: visible-light irradiation (a) and simulated-daylight irradiation (b), recyclability of $\mathrm{Au} @ \mathrm{r}-\mathrm{GO} / \mathrm{TiO}_{2}$ nanoparticles in $\mathrm{H}_{2}$ production under visible-light irradiation (c). (Panels B and C reproduced with permission from Ref. [98], Copyright (c) 2016 American Chemical Society.) 
UV light because of high recombination of photogenerated electron-hole pairs and a wide band gap; this results in inefficient use of visible light. However, this drawback can be overcome by either encapsulating a noble metal core within a $\mathrm{TiO}_{2}$ shell or heavy doping with carbon and nitrogen $[58,59,89,93,97]$. The production of $\mathrm{H}_{2}$ gas by water splitting using a semiconductor as a heterogeneous photocatalyst is a more attractive technique for $\mathrm{H}_{2}$ gas generation than methods such as partial oxidation, gasification, and steam reforming $[87,88]$. Core-shell-nanostructured photocatalysts, e.g.

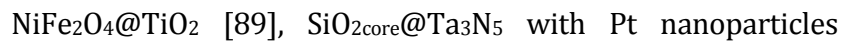
loaded on the inner shell and $\mathrm{IrO}_{2}$ or $\mathrm{CoO}_{x}$ loaded on the outer shell [92], and $\mathrm{SrTiO}_{3 \text { core: }} \mathrm{La} / \mathrm{Rh}$ core-shell particles [95], have high photocatalytic activities in water splitting.

Yolk-shell-nanostructured photocatalysts have rarely been reported because this is a relatively new concept. To the best of our knowledge, only a few YSNs have been synthesized and tested in photocatalytic water splitting. Nanoparticles consisting of a noble metal core/yolk in a semiconductor shell have distinct advantages. (1). A noble metal core/yolk encapsulated in a semiconductor shell transfers the charges created during light absorption, which helps to prevent aggregation. (2). A noble metal has a very low Fermi energy level, which can extend the catalyst life and improve the performance. (3). Reduction and oxidation of water occur on the core/yolk and shell, respectively, and this minimizes the possibility of recombination, as shown in Fig. 6(A) [59,94].

Multishelled hollow nanoreactors, h-(Pt-TiO 2$) / C d S$, consisting of hollow $\mathrm{TiO}_{2}$ and $\mathrm{CdS}$ porous double shells with fine $\mathrm{Pt}$ nanoparticles deposited on the inner surface of the $\mathrm{TiO}_{2}$ shell, were synthesized using an in situ growth and deposition method. Carboxyl-modified poly(methyl methacrylate) nanospheres were used as templates, and after deposition of $\mathrm{Pt}$, $\mathrm{TiO}_{2}$, and $\mathrm{CdS}$, the templates were removed by calcination in air in order to create a hollow structure [87]. h-(Pt-TiO 2$) / \mathrm{CdS}$ nanospheres of size approximately $318 \mathrm{~nm}$ with shells of thickness $25 \mathrm{~nm}$ and Pt nanoparticles of diameter $5 \mathrm{~nm}$ were tested in water splitting. They showed an excellent catalytic activity of $296 \mu \mathrm{mol} / \mathrm{h} / 10 \mathrm{mg}$ and apparent quantum efficiency (QE) of $14.5 \%$ at a wavelength of $420 \mathrm{~nm}$ [87]. Analysis suggests that the specific morphology and the composites contributed to the outstanding catalytic activity. The use of CdS as the outer shell enhanced the reception of visible light and accurately directed photogenerated carriers to the inner $\mathrm{TiO}_{2}$ shell (active sites); the Pt nanoparticles in the inner layer increased the reaction rate and the porous and hollow structures enabled sufficient transfer of molecules [87].

A composite consisting of $\mathrm{Ni}$ metal and $\mathrm{ZnO}(7-23 \mathrm{~nm})$ enclosed in porous carbon shells, (Ni-ZnO)@C, is an efficient photocatalyst for generating $\mathrm{H}_{2}$ gas. $\mathrm{Ni}$ and $\mathrm{ZnO}$ are the main active sites. This yolk-shell structure was formed by partial etching of $\mathrm{Ni}$ and $\mathrm{ZnO}$ from (Ni-ZnO)@C core-shell nanoparticles [88]. The porous carbon shell allows reactants to diffuse freely through the shell. (Ni-ZnO)@C with a $\mathrm{Ni} / \mathrm{Zn}$ molar ratio of 1 gave the best results, and $\mathrm{H}_{2}$ gas production from seawater splitting using (Ni-ZnO)@C was approximately 20.8 times higher than that using bare $\mathrm{TiO}_{2}$ nanoparticles [88].
Wang et al. [98] recently used graphene in a yolk-shell nanoreactor composite for photocatalytic applications. They reported that graphene hybridized with $\mathrm{TiO}_{2}$ suppressed recombination of electron-hole pairs and enhanced light absorption. A nanoreactor consisting of Au nanoparticles encapsulated in a hybrid shell consisting of reduced graphene oxide and $\mathrm{TiO}_{2}$ (Au@r-GO/TiO ${ }_{2}$ ) was prepared using a sol-gel coating process, calcination, and selective template etching; the nanoreactor showed high water splitting photocatalytic activity, with a $\mathrm{H}_{2}$ production rate of $462 \mu \mathrm{mol} \mathrm{h}^{-1} \mathrm{~g}^{-1}$ and an apparent QE of $2.5 \%$. Tests showed that the catalyst had high stability, with no obvious loss of activity after six cycles. Some yolk-shell microreactors also gave excellent catalytic performances in water splitting for $\mathrm{H}_{2}$ production, such as yolk-shell TiN microparticles [99], yolk-shell $\mathrm{MoS}_{2}$ microparticles [100], and $\mathrm{KNb}_{3} \mathrm{O}_{8}$ yolk-shell microspheres [101].

Reduction of $\mathrm{CO}_{2}$ through light absorption, which mimics natural photosynthesis, converts $\mathrm{CO}_{2}$ and $\mathrm{H}_{2} \mathrm{O}$ to hydrocarbon fuels such as methane, methanol, formaldehyde, ethanol, and formic acid, and $\mathrm{O}_{2}$ [102-107]. The reduction of $\mathrm{CO}_{2}$, which is abundant, is an attractive sustainable energy production method and also helps to reduce this greenhouse gas in the environment. $\mathrm{CO}_{2}$ is an extremely stable molecule and is difficult to activate for chemical reactions. In traditional methods, high temperatures and electrical voltages are needed to break $\mathrm{CO}_{2}$ molecules, and this is unsustainable and costly [103]. In 1979 , selective reduction of $\mathrm{CO}_{2}$ was first achieved using a photocatalytic method to produce hydrocarbon fuel [102]. So far, a number of semiconductors have been identified as effective photocatalysts for $\mathrm{CO}_{2}$ reduction in the liquid or gas phase, e.g. $\mathrm{TiO}_{2}, \mathrm{CdS}, \mathrm{ZnGa}_{2} \mathrm{O}_{4}$, and $\mathrm{ZnGe}_{2} \mathrm{O}_{4}$, [102,104,101-109]. $\mathrm{TiO}_{2}$ is a good semiconductor photocatalyst, but it has low photocatalytic activity under UV irradiation for selective reduction of $\mathrm{CO}_{2}$. Cocatalysts are therefore needed to obtain better catalytic performances. Noble or coinage metals such as $\mathrm{Au}, \mathrm{Ag}, \mathrm{Pt}, \mathrm{Pd}$, $\mathrm{Rh}$, and $\mathrm{Cu}$ are suitable cocatalyst materials $[108,110]$. The mechanism of photocatalytic reduction involves the formation of $\mathrm{H}$ atoms, $\mathrm{C}-\mathrm{O}$ bond breaking, and $\mathrm{C}-\mathrm{H}$ and $\mathrm{O}-\mathrm{H}$ bond formation under UV irradiation with a catalyst, in the presence of $\mathrm{H}_{2} \mathrm{O}$ and $\mathrm{CO}_{2}$ (as shown in Fig. 7(A)) [102,104].

A combination of mesoporous $\mathrm{Au} @ \mathrm{TiO}_{2}$ YSNs and an induced electric field provides an effective catalytic system for reduction of $\mathrm{CO}_{2}$. Such plasmonic metal/semiconductor hybrid nanoparticles have recently been shown to be good potential candidates for use in many photocatalytic applications. $\mathrm{Au} @ \mathrm{TiO}_{2}$ nanoparticles of size 200-250 nm with an average shell thickness of around $50 \mathrm{~nm}$ and a Au core of diameter 45 nm were synthesized using a hydrolysis-deposition method. First, carbon was coated on the Au nanoparticle surface before deposition of $\mathrm{a} \mathrm{Ti}_{2}$ layer; the carbon layer acted as a sacrificial template and was removed to create voids between the core and the shell [107]. Catalytic tests indicated that $\mathrm{Au} @ \mathrm{TiO}_{2}$ YSNs gave a very high photoreduction yield of $\mathrm{CO}_{2}$, with a $\mathrm{CH}_{4}$ production rate of $2.52 \mu \mathrm{mol} \mathrm{h}-1 \mathrm{~g}^{-1}$, which is about 3.6 times higher than that achieved using the commercial catalyst P25, and generation of the more valuable high-grade carbon compound $\mathrm{C}_{2} \mathrm{H}_{6}$ at a rate of $1.67 \mu \mathrm{mol} \mathrm{h} \mathrm{h}^{-1} \mathrm{~g}^{-1}$ under UV-vis-light irradiation 


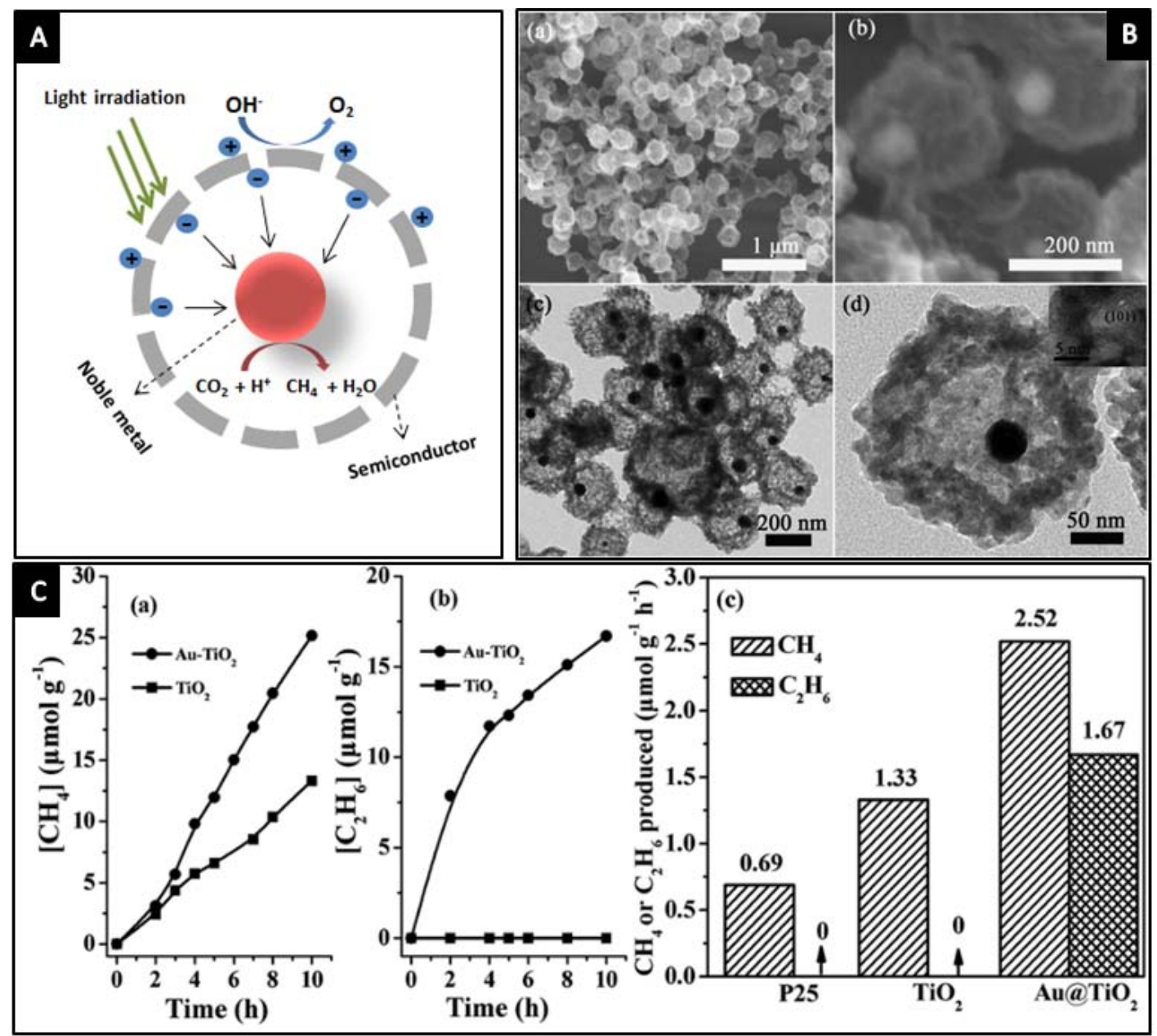

Fig. 7. (A) Schematic diagram of $\mathrm{CO}_{2}$ reduction mechanism using noble metal@semiconductor YSNs; (B) SEM (a, b) and TEM (c, d) images of Au@TiO YSNs (inset in $\mathrm{d}$ is high-resolution TEM image); (C) $\mathrm{CH}_{4}$ (a) and $\mathrm{C}_{2} \mathrm{H}_{6}$ (b) production catalysed by $\mathrm{Au}_{0} \mathrm{TiO}_{2} \mathrm{YSNs}$ and bare hollow $\mathrm{TiO}_{2}$ spheres, com-

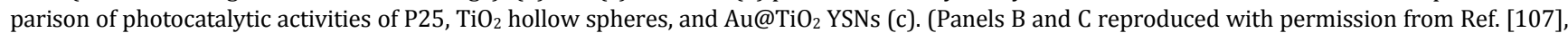
Copyright (C) The Royal Society of Chemistry 2015.)

[107]. Analysis suggests that plasmonic metal/semiconductor hybrid nanoreactors combined with an applied electric field can promote the generation and subsequent separation of electron-hole pairs at catalytic active sites, leading to an improved catalytic performance and production of high-grade carbon species. Titanate nanosheet-assembled yolk-shell microspheres have also been synthesized and tested for photocatalytic $\mathrm{CO}_{2}$ reduction; they showed excellent catalytic activity [111].

Recently, a yolk-shell catalyst consisting of carbon nanospheres encapsulated in hollow $\mathrm{TiO}_{2}$ shells $\left(\mathrm{C} @ \mathrm{TiO}_{2}\right)$ was synthesized by coating carbon with a uniform layer of $\mathrm{TiO}_{2}$ by hydrolysis and condensation, followed by calcination at $450{ }^{\circ} \mathrm{C}$; the catalyst nanoparticle diameter was approximately $420 \mathrm{~nm}$ and the size of the encapsulated yolk was $350 \mathrm{~nm}$ [112]. Photocatalytic tests were performed in a custom-made Pyrex glass reactor at room temperature and atmospheric pressure under simulated solar light $(\lambda>200)$. A C@ $\mathrm{TiO}_{2}$ sample calcined for $120 \mathrm{~min}$ had the best catalytic activity in production of both methane and methanol. The methane production rate achieved with $\mathrm{C} @ \mathrm{TiO}_{2}\left(4.22 \mu \mathrm{mol} \mathrm{h}^{-1} \mathrm{~g}^{-1}\right)$ was about twice that obtained using the commercial catalyst P25 [112]. This shows that car- bon played a crucial role in boosting the photocatalytic performance in $\mathrm{CO}_{2}$ reduction.

Not many yolk-shell-nanostructured photocatalysts have been tested in the photocatalytic reduction of $\mathrm{CO}_{2}$. Here, we introduce a few core-shell nanoreactors. Ni@NiO/InTaO ${ }_{4}-\mathrm{N}$ core-shell nanoparticles were synthesized and showed enhanced photocatalytic activity. The production yield achieved from $\mathrm{CO}_{2}$ reduction was higher than those obtained using In$\mathrm{TaO}_{4}-\mathrm{N}$ and as-prepared $\mathrm{InTaO}_{4}[59,109]$. The Ni metal core was encapsulated in two shell layers, consisting of $\mathrm{NiO}$ and $\mathrm{InTaO}_{4}-\mathrm{N}$. In this photocatalyst, $\mathrm{Ni@NiO} \mathrm{acts} \mathrm{as} \mathrm{a} \mathrm{cocatalyst,}$ which improves the photocatalytic performance of $\mathrm{InTaO}_{4}$. $\mathrm{Cu} / \mathrm{Pt} / \mathrm{TiO}_{2}$ core-shell nanoparticles were also synthesized and tested. This nanoparticle composite gave good selectivity for $\mathrm{CO}_{2}$ reduction, i.e. 85\%, compared with those of $\mathrm{Pt} @ \mathrm{TiO} 2$ and $\mathrm{Cu} @ \mathrm{TiO}_{2}$, which gave selectivities of $41 \%$ and $80 \%$, respectively [108]. Ag-doped multiwalled carbon nanotubes@ $\mathrm{TiO}_{2}$ (MWCNT@TiO 2 ) core-shell nanoparticles were fabricated for reduction of $\mathrm{CO}_{2}$ to methane and ethylene. This nanoreactor gave the best catalytic performance at a Ag weight percentage of $2 \%$ [110]. It is believed that more yolk-shell-nanostructured photocatalysts for reduction of $\mathrm{CO}_{2}$ will be developed. The ad- 
vantages of yolk-shell structures will lead to better catalytic performances.

Pollutant degradation, another application of photocatalysis, uses visible light and appropriate photocatalysts to effectively remove organic contaminants from wastewater. Semiconductors are again efficient photocatalysts, and combinations of the most popular semiconductor, $\mathrm{TiO}_{2}$, and cocatalysts have been widely used. Recently, a number of yolk-shell photocatalysts for photocatalytic degradation of pollutants have been reported, some of which are micro-sized nanoparticles, and are briefly introduced here. ZnO hollow spheres with a double-yolk structure, formed by bubble-assisted Ostwald ripening, gave more than $90 \%$ degradation of rhodamine B (RhB) [113]. $\mathrm{Ti}^{3+}$ self-doped titanium oxide YSNs aggregated into micro-sized spheres to form $\mathrm{TiO}_{2}$ powders, which gave $\mathrm{RhB}$ degradation percentages of $80.3 \%, 98.2 \%$, and $99.3 \%$ in 5,20 , and $30 \mathrm{~min}$, respectively [58]. Ag-loaded nitrogen-doped yolk-shell mesoporous $\mathrm{TiO}_{2}$ hollow microspheres were also investigated and gave good catalytic performances in the photodegradation of both $\mathrm{RhB}$ and the antibiotic ciprofloxacin [114]. Yolk-shell-structured $\mathrm{Bi}_{4-2 x} \mathrm{Mo}_{x} \mathrm{O}_{6}(x \leq 1)$ microspheres were synthesized; $\mathrm{Bi}_{2.38} \mathrm{Mo}_{0.81} \mathrm{O}_{6}$ synthesized via a solvothermal method had the best catalytic activity, giving 99\% degradation of $\mathrm{RhB}$ and $72 \%$ degradation of methyl orange after $120 \mathrm{~min}$ [115]. Yolk-shell Au@ $\mathrm{CeO}_{2}$ microspheres showed good catalytic activity and gave 95\% decolouration of methylene blue at room temperature in $40 \mathrm{~min}$ [116].

A yolk-shell-structured nano-sized catalyst, namely the $\mathrm{Au} @ \mathrm{r}-\mathrm{GO} / \mathrm{TiO}_{2}$ yolk-shell nanoreactor which was also used for water splitting, was investigated for photocatalytic decomposition of $\mathrm{RhB}$. The nanoreactor gave $99.6 \% \mathrm{RhB}$ degradation in 50 min, with a QE of 3.4\%, under simulated daylight; this is much higher than the degradation achieved using the commercial catalyst P25 under the same conditions [98]. This nanoreactor had good catalytic stability, although the catalytic activity declined slightly after six runs. The good catalytic performance is attributed to the graphene-hybridized $\mathrm{TiO}_{2}$ shell, as previously discussed.

$\mathrm{Fe}_{3} \mathrm{O}_{4} @ \mathrm{C} @ \mathrm{TiO}_{2} \mathrm{YSN}$, which consist of a $\mathrm{Fe}_{3} \mathrm{O}_{4}$ core coated with a carbon layer and a $\mathrm{Fe}_{3} \mathrm{O}_{4} @ \mathrm{C}$ yolk encapsulated in a mesoporous $\mathrm{TiO}_{2}$ shell, were also tested in pollutant degradation. These YSNs were synthesized by self-assembly of poly(acrylic acid) (PAA), which was used as a template, on suspended $\mathrm{Fe}_{2} \mathrm{O}_{3}$ nanoparticles to form $\mathrm{Fe}_{2} \mathrm{O}_{3} @$ @PA core-shell nanoparticles. The addition of tetrabutyl titanate resulted in aggregation of small amorphous $\mathrm{TiO}_{2}$ nanoparticles on the PAA layer. A porous $\mathrm{TiO}_{2}$ shell was formed through formation of anatase nanocrystals from amorphous particles by annealing. Finally, heat treatment of the $\mathrm{Fe}_{2} \mathrm{O}_{3} @ \mathrm{PAA} @ \mathrm{TiO}_{2}$ core-shell nanoparticles reduced the PAA to carbon and $\mathrm{Fe}_{2} \mathrm{O}_{3}$ to $\mathrm{Fe}_{3} \mathrm{O}_{4}$, with simultaneous void formation between carbon and $\mathrm{TiO}_{2}$ [117]. This novel method gave an excellent multifunctional photocatalyst with a large surface area and magnetic properties. Experimental results for RhB photodegradation showed that $\mathrm{Fe}_{3} \mathrm{O}_{4} @ \mathrm{C} @ \mathrm{TiO}_{2}$ YSNs had excellent catalytic activity during five cycles [117]. The magnetic cores enabled easy recovery of the catalyst using an external magnetic field.
Joo et al. [118] reported fabrication of ${\mathrm{C} @ \mathrm{TiO}_{2}}$ yolk-shell-nanostructured particles with a tuneable size, crystallinity, and phase for pollutant degradation. $\mathrm{C@TiO}_{2}$ was prepared using a templating method with silica-protected calcination and selective etching, in which the silica layer acted as a protecting layer and helped to maintain the structural integrity of the $\mathrm{TiO}_{2}$ shells during high-temperature calcination. Post-treatments, namely acid treatment and recalcination, were performed to improve the crystallinity of the $\mathrm{TiO}_{2}$ shells, which was a significant factor in the photocatalytic performance. The catalytic activity in $\mathrm{RhB}$ degradation of a sample post-treated and calcined at $750{ }^{\circ} \mathrm{C}$ was better than those of samples without post-treatments, with post-treatments but calcined at different temperatures, and commercial P25 $\mathrm{TiO}_{2}$ [118]. It is believed that not only the crystallinity degree of $\mathrm{TiO}_{2}$ but also the carbon material used in the nanoreactor had positive effects on photocatalysis.

Recently, a nanoreactor consisting of a magnetic material, a noble metal, and a semiconductor was synthesized and used in photocatalytic degradation of pollutants. This nanoreactor has several distinct advantages in terms of its composition; the combination of a noble metal/plasmonic metal with a semiconductor results in local surface plasmon resonance adsorption, which enhances the catalytic activity, and the magnetic material improves the recyclability by enabling separation of the nanoreactor using an external magnetic field. A sea-urchin-like $\mathrm{Fe}_{3} \mathrm{O}_{4} @ \mathrm{TiO}_{2} @ \mathrm{Ag}$ yolk-shell nanoreactor with $\mathrm{Ag}(4 \mathrm{~nm})$ nanoparticles loaded on both the $\mathrm{TiO}_{2}$ surface and inside the cavities, with $\mathrm{Fe}_{3} \mathrm{O}_{4}$ as the core and nanofiber $\mathrm{TiO}_{2} / \mathrm{Fe}_{3} \mathrm{O}_{4} / \mathrm{Ag}$ nano-heterojunctions as the shell, was prepared using a modified hydrothermal method and photochemical reduction (Fig. 8). The nanoreactor showed excellent photocatalytic activity in ampicillin (AMP) degradation under both UV and visible-light irradiation [119]. The degradation rates reached $98.7 \%$ under UV irradiation and 91.5\% under visible-light irradiation; these results show that the catalytic activity of this nanoreactor is better than those of $\mathrm{Fe}_{3} \mathrm{O}_{4} @ \mathrm{TiO}_{2}$ and $\mathrm{Fe}_{3} \mathrm{O}_{4}$ particles [119]. In terms of recyclability, such yolk-shell nanoreactors can be easily separated by magnetic force and no change in the photocatalytic activity was observed after five cycles. Moreover, this facile synthetic method enables precise and easy control of the cavity size, shell thickness, and particle size.

\subsection{Electrocatalysis}

Fuel cells are energy-conversion devices with low emissions of environmentally hazardous compounds. Fuel cells convert chemical energy to electrical energy via a series of reduction and oxidation reactions at the anode, i.e. the hydrogen evolution/oxidation reaction or methanol oxidation reaction (MOR), and cathode, i.e. oxygen reduction reaction (ORR) or oxygen evolution reaction (OER) [120,121]. Proton exchange membrane fuel cells (PEMFCs) (Eq. 3) and direct methanol fuel cells (DMFCs) (Eq. 4) are the two main types of fuel cell. Fuel cells are important for green energy generation and can be used as portable power sources, e.g. in portable electronic devices or 


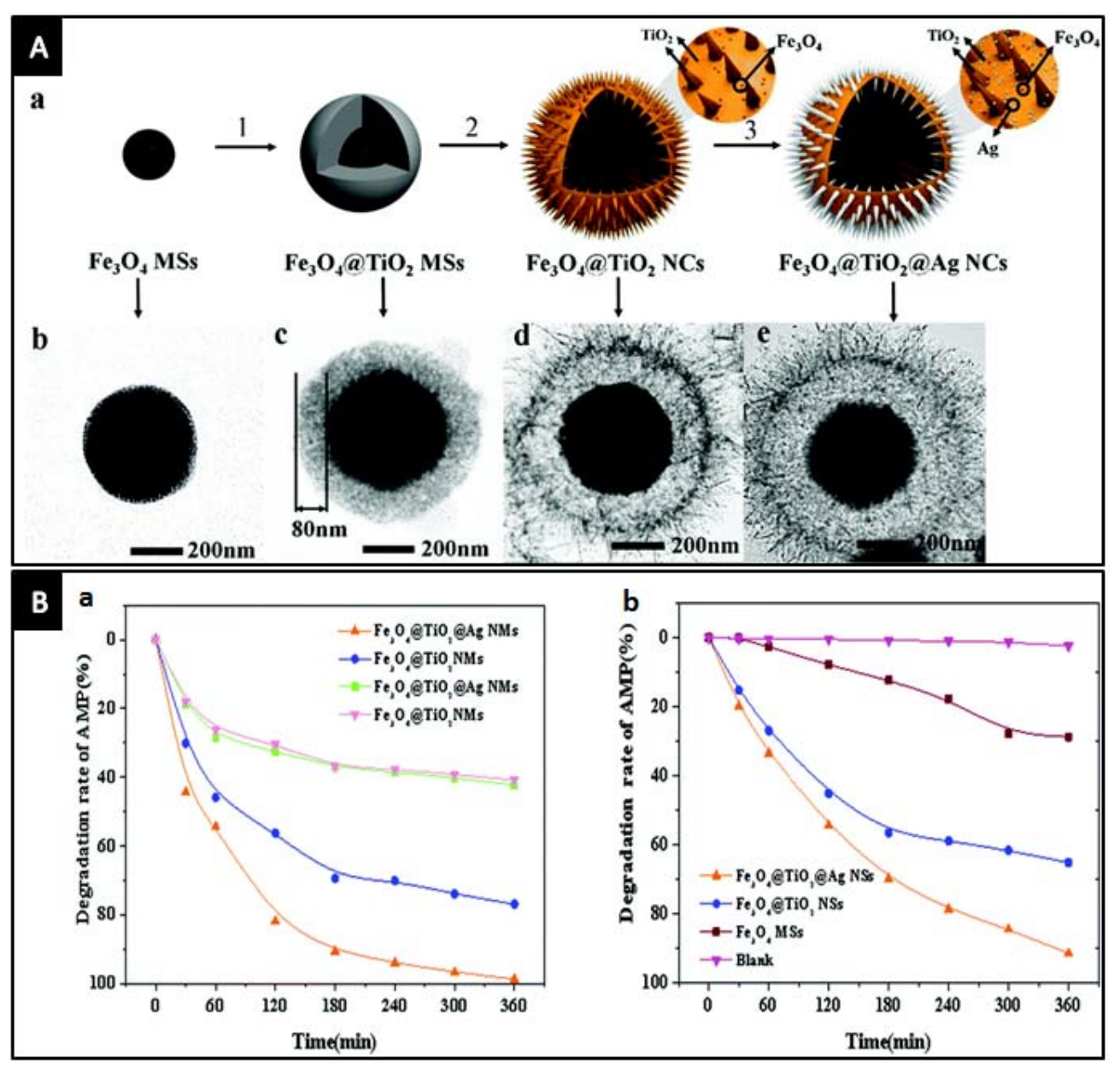

Fig. 8. (A) Schematic diagram of synthesis of $\mathrm{Fe}_{3} \mathrm{O}_{4} @ \mathrm{TiO}_{2} @ \mathrm{Ag}$ YSNs (a), and TEM images at synthetic steps (b-e); (B) results for AMP photodegradation under UV irradiation (a) and visible-light irradiation (b). (Panels A and B reproduced with permission from Ref. [119]. Copyright (C) The Royal Society of Chemistry 2016.)

batteries. Fuel cell applications have been extensively researched; however, the sluggish kinetics of the ORR at the cathode is still a challenge [122-124]. In recent decades, researchers have investigated electrode materials which enhance the performances of fuel cells. The electrocatalyst is the critical factor in the fuel cell performance [125]. Pt is the most commonly used electrocatalyst for fuel cells, but a pure Pt electrocatalyst suffers from CO poisoning because of its low CO tolerance, which leads to insufficient catalytic activity, high costs, and low durability. Many alternative metals, metal-free materials, and catalysts with various structures, such as non-precious metals, nitrogen-doped carbons, Pt-based alloys, and core-shell or yolk-shell catalysts, have been therefore been intensively investigated [120-124,126-131]. In terms of current commercial electrocatalysts, Pt loaded on a carbon support (Pt/C) gives excellent catalytic performances [127]. A good catalyst can improve the fuel cell performance in many ways, e.g. in terms of durability, stability, and catalytic activity. The ideal electrocatalyst should therefore have the following properties: (1). a high surface area; (2). high conductivity; (3). high porosity and pore accessibility; and (4). good electrochemical stability, even under harsh reaction conditions.

Eq. 3: PEMFC reactions

$$
\begin{array}{ll}
\text { Cathode } & 1 / 2 \mathrm{O}_{2}+2 \mathrm{H}^{+}+2 \mathrm{e}^{-} \rightarrow \mathrm{H}_{2} \mathrm{O} \\
\text { Anode } & \mathrm{H}_{2} \rightarrow 2 \mathrm{H}^{+}+2 \mathrm{e}^{-} \\
\text {Overall } & 1 / 2 \mathrm{O}_{2}+\mathrm{H}_{2} \rightarrow \mathrm{H}_{2} \mathrm{O} \\
\text { Eq. 4: DMFCs reactions } \\
\text { Cathode } & 3 / 2 \mathrm{O}_{2}+6 \mathrm{H}^{+}+6 \mathrm{e}^{-} \rightarrow 3 \mathrm{H}_{2} \mathrm{O} \\
\text { Anode } & \mathrm{CH}_{3} \mathrm{OH}+\mathrm{H}_{2} \mathrm{O} \rightarrow \mathrm{CO}_{2}+6 \mathrm{H}^{+}+6 \mathrm{e}^{-} \\
\text {Overall } & \mathrm{CH}_{3} \mathrm{OH}+3 / 2 \mathrm{O}_{2} \rightarrow \mathrm{CO}_{2}+2 \mathrm{H}_{2} \mathrm{O}
\end{array}
$$

The MOR is the key reaction at the anode in DMFCs, which are promising power sources for portable electronic devices and electric vehicles. Here, we discuss a few yolk-shell-nanostructured electrocatalysts for the MOR. The MOR activity of a Au@Pt yolk-shell electrocatalyst of diameter approximately $100 \mathrm{~nm}$, which was synthesized using a galvanic displacement method, was investigated [126]. The experimental results showed that this electrocatalyst had high CO tolerance, which prolonged the Pt durability, good catalytic activity, and a significantly decreased MOR overpotential. The MOR activity of a $\mathrm{Fe}_{3} \mathrm{O}_{4}$-polydopamine-graphene-Pt yolk-shell nanocomposite $\left(\mathrm{Fe}_{3} \mathrm{O}_{4} @ \mathrm{PDA} / \mathrm{RGO} / \mathrm{Pt}\right)$ was also investigated. First, a $\mathrm{Fe}_{3} \mathrm{O}_{4}$ yolk was coated with PDA to prepare core-shell nanoparticles, and then with RGO, which acted as a shell or support, was formed using a hydrothermal process to immobilize $\mathrm{Fe}_{3} \mathrm{O}_{4} @ \mathrm{PDA}$ and prevent particle agglomeration. Pt nano- 
particles were then distributed on the PDA shell and RGO, and voids were formed between the yolk and shell by partial dissolution of the yolk [129]. The catalytic activity of this yolk-shell electrocatalyst was about 2.6 times that of a commercial catalyst because of its smaller size, better distribution of Pt nanoparticles, good catalyst support, and larger number of functional groups. Highly dispersed and porous Au@pPt YSNs (140 nm) with Pt shells of thickness approximately $20 \mathrm{~nm}$, Au yolks of size $15 \mathrm{~nm}$, and pores of size $6 \mathrm{~nm}$ were created by Pt deposition and selective etching; a silica layer, which was used as a template, was coated on the Au core surface before the outer Pt shell was removed to form a yolk-shell structure [121]. This nanoreactor gave a current density about 1.9 times higher than that obtained using commercial Pt black under acidic conditions, and better catalytic activity and stability under alkaline conditions, as shown in Fig. 9. Finally, the physical and chemical properties of a micro-sized catalyst, consisting of $\mathrm{PtCu}$ alloy yolk-shell cubes prepared via disproportionation and displacement reactions in $\mathrm{Cu}_{2} \mathrm{O}$ yolk-shell cubes, differed from those of ordinary spherical nanoparticles because its crystal planes were different. The PtCu alloy yolk-shell nanocubes had good MOR activity in acidic solution, about 2.5 times better than that of a commercial Pt/C electrocatalyst [127].

The ORR occurs at the cathode in both PEMFCs and DMFCs. As already mentioned, the sluggish kinetics of this reaction is a major challenge in fuel cell development. Appropriate electrocatalysts are therefore needed to improve the ORR kinetics. It has been suggested that the ORR kinetics involves two pathways: one is direct four-electron pathway and the other is an indirect (peroxide) pathway $[130,132]$. Many efficient catalysts have been suggested, but not many of them have nanoscale yolk-shell structures. Here, we present two recent examples of core-shell nanoparticles and yolk-shell-structured nano-electrocatalysts, and some yolk-shell microreactors.

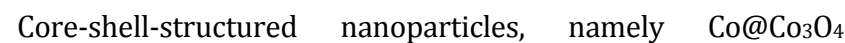
core-shell nanoparticles embedded in bamboo-like nitrogen-doped carbon nanotubes ( $\mathrm{Co} @ \mathrm{Co}_{3} \mathrm{O}_{4}$ /BNCNTs), were prepared via thermal treatment and oxidation [124]. Tests showed that the Co/BNCNTs did not show effective catalytic activity

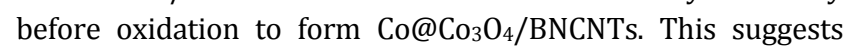
that a $\mathrm{Co}_{3} \mathrm{O}_{4}$ composite provides the active sites for the ORR reaction and the catalytic activity is related to the level of oxidation. These YSNs had moderate catalytic activity, excellent tolerance for methanol molecules, and better catalytic stability than commercial Pt black [124]. Recently, highly active and durable PdAg@Pd core-shell nanoparticles were prepared and were shown to be a good potential ORR catalyst. PdAg bimetallic alloy nanoparticles of size approximately $6 \mathrm{~nm}$ were prepared via oleylamine reduction of $\mathrm{Pd}$ and $\mathrm{Ag}$ precursors, and ultrathin Pd shells were formed by electrochemical treatment (100 cycles of electrocatalysis) of the PdAg alloy in an acidic medium [133]. The electrocatalytic activity was evaluated by attaching the nanoparticles to active carbon; the nanoparticles showed good catalytic activity and durability in the ORR.

The Au@pPt porous yolk-shell nanoreactor, which, as mentioned above, was used in the MOR, was also tested in the ORR using $\mathrm{O}_{2}$-saturated $0.1 \mathrm{~mol} / \mathrm{L} \mathrm{KOH}$. The catalytic activity of this nanoreactor was better than that of hollow Pt and Pt black, and it gave an onset potential of $0.12 \mathrm{~V}$, which is a $30 \mathrm{mV}$ positive shift from the onset potential of hollow Pt and a positive shift double that from the onset potential of Pt black [121]. This proves that the Au@pPt catalyst has good catalytic activities in both the MOR and ORR. Iron carbide was also found to play a significant role in improving electrocatalytic performances in the ORR. $\mathrm{Fe}_{2.5} \mathrm{C}$ buried in a nitrogen-doped carbon shell togetherwith an $\mathrm{Fe}_{3} \mathrm{O}_{4}$ core $\left(\mathrm{Fe}_{3} \mathrm{O}_{4} @ \mathrm{Fe}_{2.5} \mathrm{C} / \mathrm{N}\right.$-doped $\left.\mathrm{C}\right)$ was fabricated using a templating approach and calcination under a nitrogen flow [122]. This yolk-shell nanoreactor with particles of size

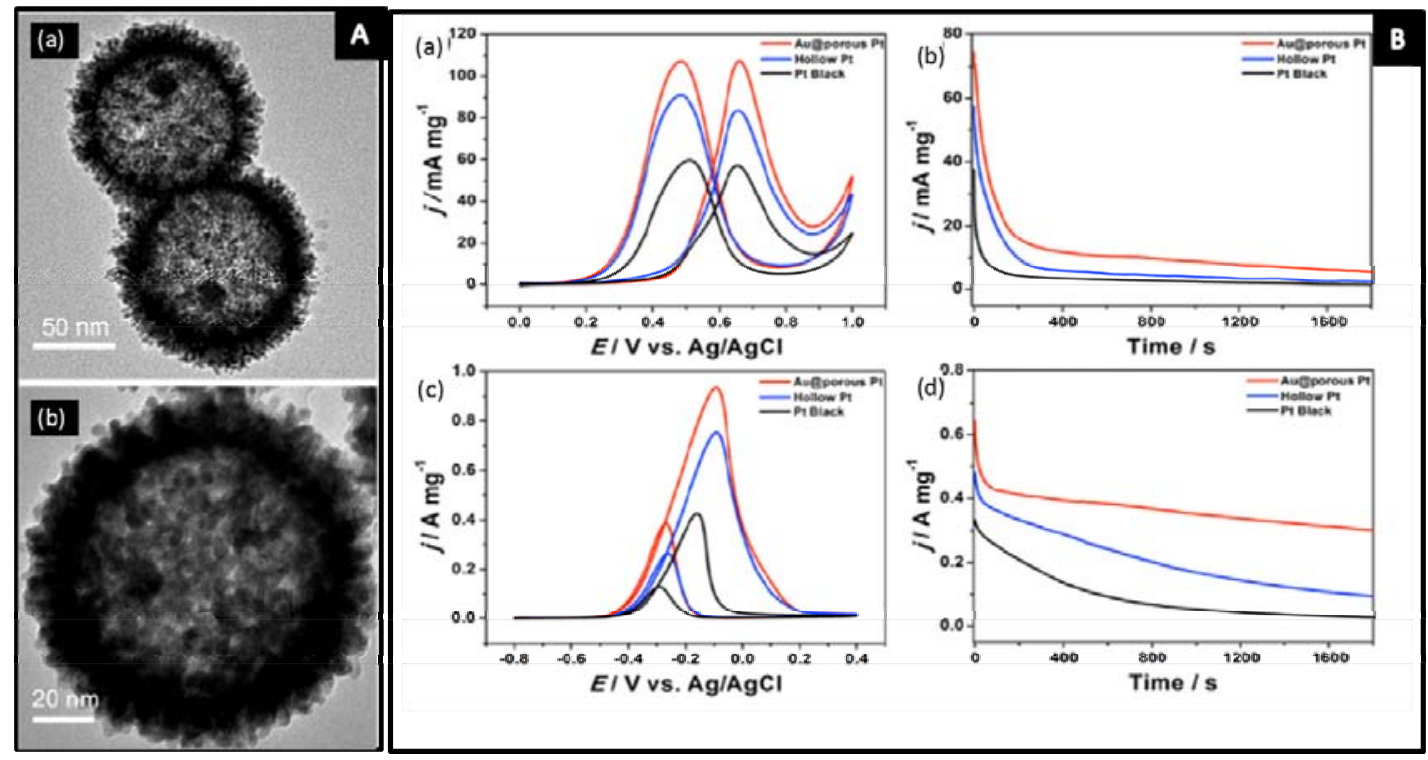

Fig. 9. (A) TEM images of Au@pPt YSNs (a, b); (B) cyclic voltammograms (a) and chronoamperometric curves (b) recorded at $0.6 \mathrm{~V}$ for MOR catalysed by Au@pPt, hollow Pt, and Pt black catalysts under acidic conditions, cyclic voltammograms (c) and chronoamperometric curves (d) recorded at -0.2 V for MOR catalysed by Au@pPt, hollow Pt, and Pt black catalysts under alkaline conditions. (Panels A and B reproduced with permission from Ref. [121]. Copyright (C) 2015 Wiley-VCH Verlag GmbH \& Co. KGaA, Weinheim.) 
400-500 nm, a shell thickness of $40 \mathrm{~nm}$, and a yolk size of 140 $\mathrm{nm}$ was tested in the ORR in alkaline solution. The experimental results show that the catalyst had high stability, with only slight decay in the activity after 1000 cycles [122]. Lou and his colleagues [134] synthesized $\mathrm{Co}_{3} \mathrm{O}_{4} / \mathrm{NiCO}_{2} \mathrm{O}_{4}$ box-in-box rattle-type double-shelled nanocages using zeolitic imidazolate framework-67/Ni-Co layered double hydroxide YSNs by thermal annealing in air. This novel synthetic method is versatile and can be used to produce double-shelled nanocages with various compositions. The catalytic performance of $\mathrm{Co}_{3} \mathrm{O}_{4} / \mathrm{NiCO}_{2} \mathrm{O}_{4}$ nanocages in which both shells were of thickness around $20 \mathrm{~nm}$ were investigated in the OER. The results show that the catalytic activity was better than those of $\mathrm{Co}_{3} \mathrm{O}_{4}$ and $\mathrm{Co}_{3} \mathrm{O}_{4} / \mathrm{Co}_{3} \mathrm{O}_{4}$ nanocages and that the catalyst had good stability. Recently, this group of researchers reported the use of a metal-organic framework to form Co-nanoparticle-embedded carbon@ $\mathrm{Co}_{9} \mathrm{~S}_{8} \quad$ (Co-C@ $@ \mathrm{Cog}_{8} \mathrm{~S}_{8}$ rattle-type double-shelled nanocages via thermal annealing of ZIF-67@a-CoS YSNs, as
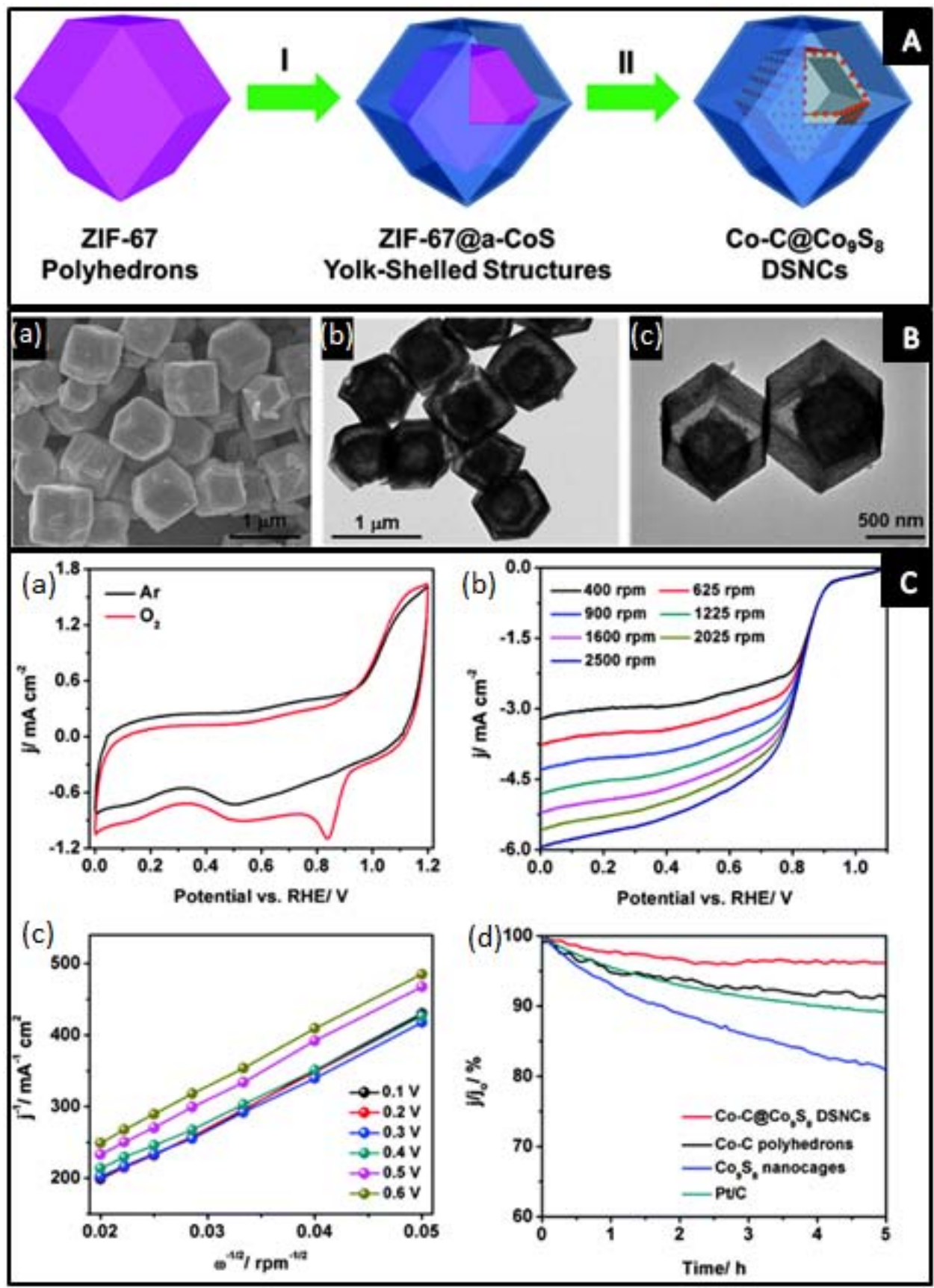

Fig. 10. (A) Schematic diagram of synthesis of Co-C@Co9$S_{8}$ double-shelled nanocages; (B) SEM image of Co-C@Co9S8 (a), TEM images of Co-C@Co9S8 (b, c); (C) cyclic voltammetry curves of $\mathrm{Co}-\mathrm{C} @ \mathrm{Co}_{9} \mathrm{~S}_{8}$ in an $\mathrm{Ar}-$ or $\mathrm{O}_{2}$-saturated $0.1 \mathrm{~mol} / \mathrm{L} \mathrm{KOH}$ solution at scanning rate of $10 \mathrm{mV} / \mathrm{s}$ (a), linear sweep voltammograms of $\mathrm{Co}_{0} \mathrm{C} @ \mathrm{Co}_{9} \mathrm{~S}_{8}$ at different rotating speeds (b), Koutecky-Levich plots of Co-C@Cog $\mathrm{C}_{8}$ at various potentials (c), and stabilities of Co-C@Cog $\mathrm{S}_{8}, \mathrm{Co}-\mathrm{C}, \mathrm{Co}_{9} \mathrm{~S}_{8}$, and Pt black at $1600 \mathrm{r} / \mathrm{min}$ in $\mathrm{O}_{2}$-saturated $0.1 \mathrm{~mol} / \mathrm{L} \mathrm{KOH}$ solution (d). (Panels A and B reproduced with permission from Ref. [135]. Copyright (C) The Royal Society of Chemistry 2016.) 
Table 4

Summary of catalytic performances of nanoreactors used in MOR and ORR.

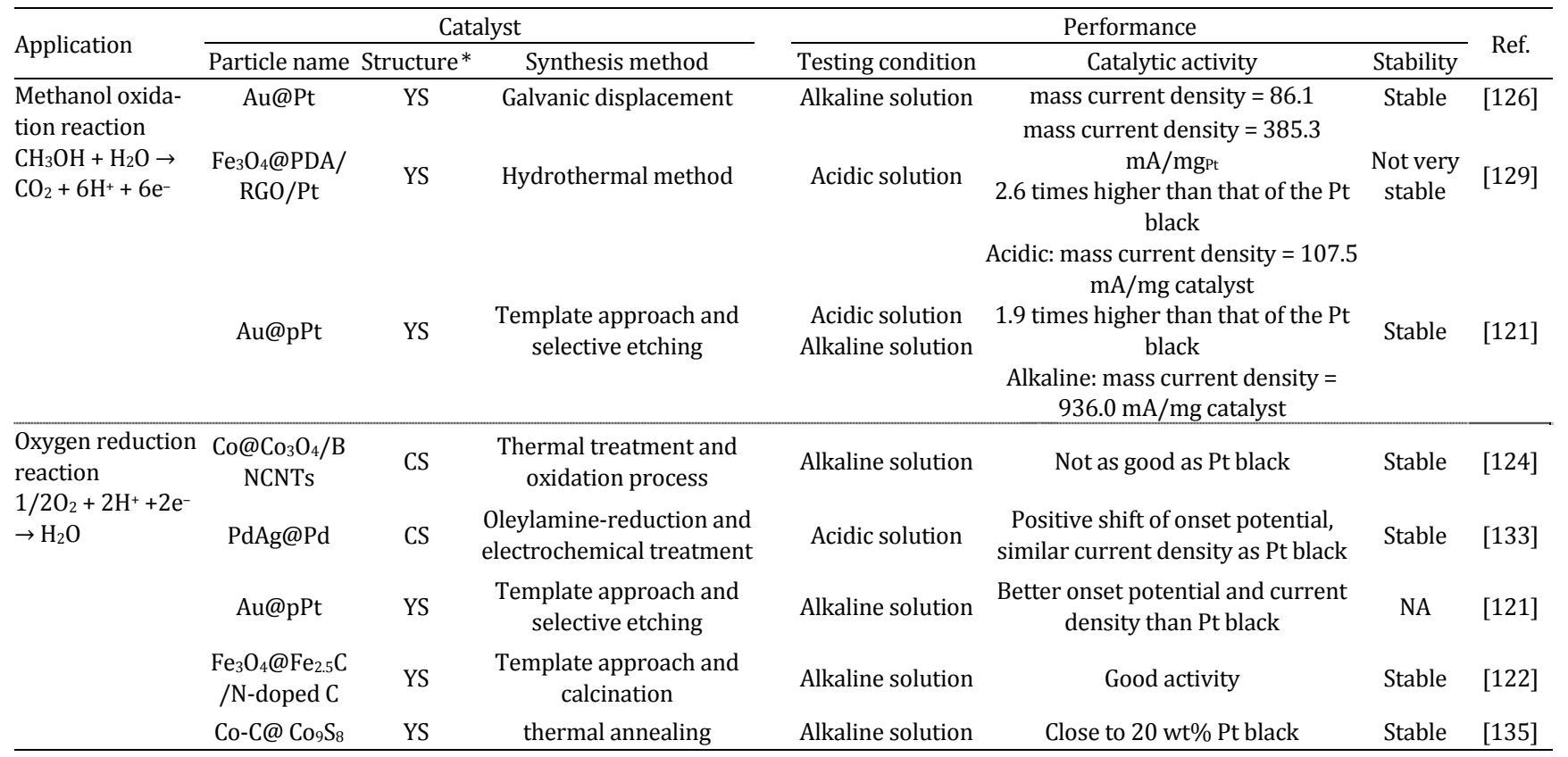

*CS: Core-shell; YS: Yolk-shell.

shown in Fig. 10(A) [135]. The electrocatalytic activity and stability in the ORR were tested. The results showed that the current density at a rotating speed of $1600 \mathrm{r} / \mathrm{min}$ reached 4.5 $\mathrm{mA} / \mathrm{cm}^{2}$ at $0.5 \mathrm{~V}$, which is much greater than the values for many other nanoparticles based on $\mathrm{Co}, \mathrm{Co}_{3} \mathrm{O}_{4}$, or carbon, and the current retention was $96 \%$ after 5 h, as shown in Fig. 10(C) [135]. Analysis suggests that for a rattle-type hollow double-shelled structure, the high exposure and accessibility of the active sites contribute to the outstanding catalytic performance. Finally, many yolk-shell-structured microparticles have been used in the ORR and shown excellent electrocatalytic activities, e.g. $\mathrm{Fe}_{3} \mathrm{O}_{4} @ \mathrm{Co}_{3} \mathrm{O}_{4}$ yolk-shell microspheres [132], yolk-shell Co- and $\mathrm{N}$-codoped porous carbon microspheres [136], yolk-shell-structured $\mathrm{La}_{0.9} \mathrm{Sr}_{0.1} \mathrm{CoO}_{3}$ perovskite microspheres [137], yolk-shell-structured N/P/B-ternary-doped biocarbon microparticles [138], and $\mathrm{Ni} 0.69 \mathrm{Co} 0.31-\mathrm{P}$ yolk-shell microspheres [139]. The catalytic performances of the discussed core-shell and yolk-shell nanoreactors used in the MOR and the ORR are summarized in Table 4.

\section{Summary and outlook}

In this review, we have summarized the general synthetic methods for yolk-shell particles, and their recent use as nanoreactors in energy-conversion applications. Precise tuning of their structures, particle sizes, and functionalities will provide next-generation YSNs with nanoarchitectures that make them attractive catalysts for many important chemical reactions.

Although many different synthetic methods have been developed in the past decade, the development of more universal, effective, environmentally friendly, and low-cost synthetic methods is still a primary research aim. Several methods for
YSN synthesis were described and compared; however, a general method for synthesizing more complex YSNs is still needed. Recently, there has been rapid growth in advanced approaches for YSN synthesis [140-143], but much research is still needed to optimize the synthetic parameters. Moreover, the complexity of the synthetic processes and lack of precise control in fabricating YSNs need to be tackled; these are the main issues preventing large-scale YSN production and their commercial use.

YSNs are designed to have significant advantages over conventionally structured catalysts; however, the use of nanoreactors is still new and limited. The components of yolk-shell structures could be selectively functionalized to enable multiple reactions to be performed simultaneously. Multifunctional catalysts are highly desirable for complex chemical reactions such as tandem reactions. Moreover, the porosity of the protective shell could be further tailored to regulate the diffusion rates of reactants to enable better control of the reaction rate, and gain direct control of the catalytic performance. Furthermore, the recyclability of YSNs with protective shells around their active core will benefit their use as nanoreactors. Precisely locating the active sites in YSNs will improve our understanding of the relationship between structure and performance, and enable cooperative catalysis to be achieved. In addition, the use of YSN nanoreactors in many major chemical reactions has not yet been tested, and further research in this area is expected.

We believe that yolk-shell nanoreactors have great potential for improving chemical reactions. Multidisciplinary studies and collaboration are needed to fully realize the potential of yolk-shell nanoreactors. Significant progress has been made in the synthesis and applications of yolk-shell nanoreactors, and 
research in this area will continue to be popular in the future. The synthesis and use of optimized yolk-shell nanoreactors for high-value chemical production is the goal.

\section{References}

[1] C. Toumey, Nat. Nanotechnol., 2009, 4, 783-784.

[2] A. Ostafin, Y. C. Chen, in Kirk-Othmer Encyclopedia of Chemical Technology, John Wiley \& Sons, Inc., 2000.

[3] J. Liu, S. Z. Qiao, J. S. Chen, X. W. Lou, X. R. Xing, G. Q. Lu, Chem. Commun., 2011, 47, 12578-12591.

[4] Y. Yang, X. Liu, X. B. Li, J. Zhao, S. Y. Bai, J. Liu, Q. H. Yang, Angew. Chem. Int. Ed., 2012, 51, 9164-9168.

[5] H. C. Zhang, H. Huang, Y. Liu, X. Han, Z. Ma, L. L. Zhang, H. T. Li, Z. H. Kang, J. Mater. Chem., 2012, 22, 20182-20185.

[6] M. Pérez-Lorenzo, B. Vaz, V. Salgueiriño, M. A. Correa-Duarte, Chem. Eur. J., 2013, 19, 12196-12211.

[7] H. Tian, X. Y. Li, L. Zeng, J. L. Gong, ACS Catal., 2015, 5, 4959-4977.

[8] A. Guiet, C. Göbel, K. Klingan, M. Lublow, T. Reier, U. Vainio, R. Kraehnert, H. Schlaad, P. Strasser, I. Zaharieva, H. Dau, M. Driess, J. Polte, A. Fischer, Adv. Funct. Mater., 2015, 25, 6228-6240.

[9] M. Priebe, K. M. Fromm, Chem. Eur. J., 2015, 21, 3854-3874.

[10] J. Liu, S. Z. Qiao, Q. H. Hu, G. Q. Lu, Small, 2011, 7, 425-443.

[11] R. X. Jin, Y. Yang, Y. C. Zou, X. C. Liu, Y. Xing, Chem. Eur. J., 2014, 20, 2344-2351.

[12] B. J. Jankiewicz, D. Jamiola, J. Choma, M. Jaroniec, Adv. Colloid Interface Sci., 2012, 170, 28-47.

[13] T. J. Yao, T. Y. Cui, X. Fang, J. Yu, F. Cui, J. Wu, Chem. Eng. J., 2013, $225,230-236$.

[14] C. H. Lin, X. Y. Liu, S. H. Wu, K. H. Liu, C. Y. Mou, J. Phys. Chem. Lett., 2011, 2, 2984-2988.

[15] G. D. Li, Z. Y. Tang, Nanoscale, 2014, 6, 3995-4011.

[16] Z. W. Li, M. Li, Z. F. Bian, Y. Kathiraser, S. Kawi, Appl. Catal. B, 2016,
188, 324-341.

[17] Q. L. Fang, S. H. Xuan, W. Q. Jiang, X. L. Gong, Adv. Funct. Mater., 2011, 21, 1902-1909.

[18] Z. Chen, Z. M. Cui, F. Niu, L. Jiang, W. G. Song, Chem. Commun., 2010, 46, 6524-6526.

[19] X. L. Fang, X. J. Zhao, W. J. Fang, C. Chen, N. F. Zheng, Nanoscale, 2013, 5, 2205-2218.

[20] J. Liu, H. Q. Yang, F. Kleitz, Z. G. Chen, T. Y. Yang, E. Strounina, G. Q. Lu, S. Z. Qiao, Adv. Funct. Mater., 2012, 22, 591-599.

[21] R. Güttel, M. Paul, C. Galeano, F. Schüth, J. Catal., 2012, 289, 100-104.

[22] S. N. Shmakov, Y. Jia, E. Pinkhassik, Chem. Mater., 2014, 26, 1126-1132.

[23] S. Wu, J. Dzubiella, J. Kaiser, M. Drechsler, X. H. Guo, M. Ballauff, Y. Lu, Angew. Chem. Int. Ed., 2012, 51, 2229-2233.

[24] B. C. Liu, Q. Wang, S. L. Yu, T. Zhao, J. X. Han, P. Jing, W. T. Hu, L. X. Liu, J. Zhang, L. D. Sun, C. H. Yan, Nanoscale, 2013, 5, 9747-9757.

[25] X. L. Liang, J. Li, J. B. Joo, A. Gutiérrez, A. Tillekaratne, I. Lee, Y. D. Yin, F. Zaera, Angew. Chem. Int. Ed., 2012, 51, 8034-8036.

[26] J. C. Park, H. Song, Nano Res., 2011, 4, 33-49.

[27] R. Purbia, S. Paria, Nanoscale, 2015, 7, 19789-19873.

[28] H. Song, Acc. Chem. Res., 2015, 48, 491-499.

[29] G. Prieto, H. Tüysüz, N. Duyckaerts, J. Knossalla, G. H. Wang, F. Schüth, Chem. Rev., 2016, 116, 14056-14119.

[30] J. Liu, S. Z. Qiao, S. Budi Hartono, G. Q. Lu, Angew. Chem. Int. Ed., 2010, 49, 4981-4985.

[31] Z. W. Li, Y. Kathiraser, S. Kawi, ChemCatChem, 2015, 7, 160-168.

[32] J. Pak, H. Yoo, Microporous Mesoporous Mater., 2014, 185, 107-112.

[33] B. C. Liu, Q. Wang, S. L. Yu, P. Jing, L. X. Liu, G. R. Xu, J. Zhang, Nanoscale, 2014, 6, 11887-11897.

[34] X. L. Fang, S. J. Liu, J. Zang, C. F. Xu, M. S. Zheng, Q. F. Dong, D. H. Sun, N. F. Zheng, Nanoscale, 2013, 5, 6908-6916.

[35] Q. Zhang, T. R. Zhang, J. P. Ge, Y. D. Yin, Nano Lett., 2008, 8, 2867-2871.

[36] J. Li, L. X. Chen, X. Li, C. C. Zhang, F. L. Zeng, Appl. Surf. Sci., 2015,

\section{Graphical Abstract}

Chin. J. Catal., 2017, 38: 970-990 doi: 10.1016/S1872-2067(17)62818-3

\section{Advanced yolk-shell nanoparticles as nanoreactors for energy conversion}

Meiwen Wang, Yash Boyjoo, Jian Pan, Shaobin Wang*, Jian Liu*

Curtin University, Australia

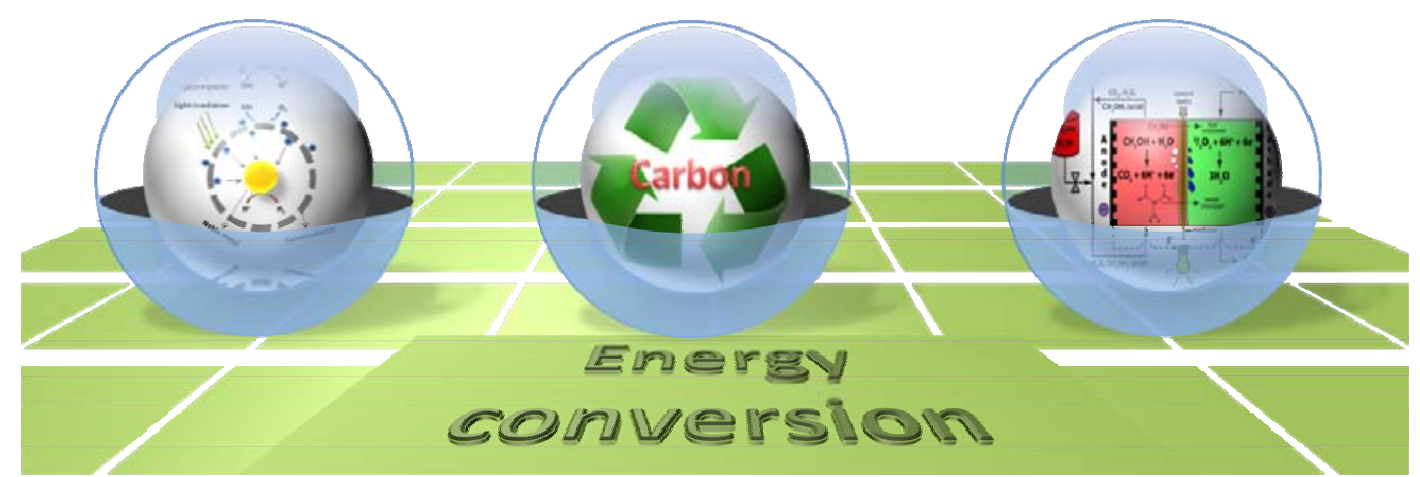

This review summarizes the general synthetic methods of yolk-shell nanoreactors and their recent catalytic performances in photocatalysis, carbon sources utilization and electrochemical energy conversion applications with an outlook of significant advantages using in more applications. 
340, 126-131.

[37] H. C. Zeng, J. Mater. Chem., 2011, 21, 7511-7526.

[38] C. C. Yec, H. C. Zeng, J. Mater. Chem. A, 2014, 2, 4843-4851.

[39] X. W. Lou, C. L. Yuan, E. Rhoades, Q. Zhang, L. A. Archer, Adv. Funct. Mater., 2006, 16, 1679-1684.

[40] Z. Y. Wang, L. Zhou, X. W. Lou, Adv. Mater., 2012, 24, 1903-1911.

[41] L. Cao, D. H. Chen, R. A. Caruso, Angew. Chem. Int. Ed., 2013, 52, 10986-10991.

[42] Z. H. Qin, H. Y. Sun, Z. Jiang, X. L. Jiao, D. R. Chen, CrystEngComm, 2013, 15, 897-902.

[43] L. Polavarapu, L. M. Liz-Marzan, Nanoscale, 2013, 5, 4355-4361.

[44] B. D. Anderson, J. B. Tracy, Nanoscale, 2014, 6, 12195-12216.

[45] A. Pearson, A. P. O'Mullane, V. Bansal, S. K. Bhargava, Chem. Commun., 2010, 46, 731-733.

[46] X. H. Xia, Y. Wang, A. Ruditskiy, Y. N. Xia, Adv. Mater., 2013, 25, 6313-6333.

[47] J. Lee, S. M. Kim, I. S. Lee, Nano Today, 2014, 9, 631-667.

[48] P. F. Xu, R. B. Yu, H. Ren, L. B. Zong, J. Chen, X. N. Xing, Chem. Sci., 2014, 5, 4221-4226.

[49] J. Jin, T. Mitome, Y. Egashira, N. Nishiyama, Colloids Surf. A, 2011, $384,58-61$.

[50] M. A. Mahmoud, R. Narayanan, M. A. El-Sayed, Acc. Chem. Res., 2013, 46, 1795-1805.

[51] Y. Chen, H. R. Chen, L. M. Guo, Q. J. He, F. Chen, J. Zhou, J. W. Feng, J. L. Shi, ACS Nano, 2010, 4, 529-539.

[52] C. Wang, J. C. Chen, X. R. Zhou, W. Li, Y. Liu, Q. Yue, Z. T. Xue, Y. H. Li, A. A. Elzatahry, Y. H. Deng, D. Y. Zhao, Nano Res., 2015, 8, 238-245.

[53] Z. Y. Zhao, J. Liu, M. Hahn, S. Z. Qiao, A. P. J. Middelberg, L. Z. He, RSC Adv., 2013, 3, 22008-22013.

[54] L. C. Kong, G. T. Duan, G. M. Zuo, W. P. Cai, Z. X. Cheng, Mater. Chem. Phys., 2010, 123, 421-426.

[55] H. C. Zeng, Curr. Opin. Chem. Eng., 2011, 1, 11-17.

[56] L. Pan, H. M. Liu, X. G. Lei, X. Y. Huang, D. H. Olson, N. J. Turro, J. Li, Angew. Chem. Int. Ed., 2003, 42, 542-546.

[57] C. Y. Dai, A. F. Zhang, J. J. Li, K. K. Hou, M. Liu, C. S. Song, X. W. Guo, Chem. Commun., 2014, 50, 4846-4848.

[58] S. X. Wang, X. J. Yang, Y. P. Wang, L. X. Liu, Y. Y. Guo, H. Guo, J. Solid State Chem., 2014, 213, 98-103.

[59] N. Zhang, S. Q. Liu, Y. J. Xu, Nanoscale, 2012, 4, 2227-2238.

[60] B. Liu, H. C. Zeng, Small, 2005, 1, 566-571.

[61] S. F. Xie, M. S. Jin, J. Tao, Y. C. Wang, Z. X. Xie, Y. M. Zhu, Y. N. Xia, Chem. Eur. J., 2012, 18, 14974-14980.

[62] W. X. Niu, L. Zhang, G. B. Xu, Nanoscale, 2013, 5, 3172-3181.

[63] K. M. Yeo, J. Shin, I. S. Lee, Chem. Commun., 2010, 46, 64-66.

[64] K. Jeong, S. M. Kim, I. S. Lee, Chem. Commun., 2015. 51, 499-502.

[65] D. Rosario-Amorin, X. Wang, M. Gaboyard, R. Clérac, S. Nlate, K. Heuzé, Chem. Eur. J., 2009, 15, 12636-12643.

[66] A. J. Majewski, J. Wood, W. Bujalski, Int. J. Hydrogen Energy, 2013, 38, 14531-14541.

[67] F. Mirzaei, M. Rezaei, F. Meshkani, Chem. Eng. Technol., 2014, 37, 973-978.

[68] D. A. J. M. Ligthart, R. A. van Santen, E. J. M. Hensen, J. Catal., 2011, 280, 206-220.

[69] X. Y. Zhao, H. R. Li, J. P. Zhang, L. Y. Shi, D. S. Zhang, Int. J. Hydrogen Energy, 2016, 41, 2447-2456.

[70] Z. Y. Lim, C. Z. Wu, W. G. Wang, K. L. Choy, H. F. Yin, RSC Adv., 2015, 5, 61925-61932.

[71] Z. F. Bian, I. Y. Suryawinata, S. Kawi, Appl. Catal. B, 2016, 195, 1-8.

[72] J. C. Park, J. U. Bang, J. Lee, C. H. Ko, H. Song, J. Mater. Chem., 2010, 20, 1239-1246.

[73] L. Li, S. C. He, Y. Y. Song, J. Zhao, W. J. Ji, C. T. Au, J. Catal., 2012, 288,
54-64.

[74] H. W. Kim, K. M. Kang, H. Y. Kwak, J. H. Kim, Chem. Eng. J., 2011, $168,775-783$.

[75] C. M. Ding, G. G. Ai, K. Zhang, Q. B. Yuan, Y. L. Han, X. S. Ma, J. W. Wang, S. B. Liu, Int. J. Hydrogen Energy, 2015, 40, 6835-6843.

[76] N. Hajjaji, M. N. Pons, A. Houas, V. Renaudin, Energy Policy, 2012, 42, 392-399.

[77] T. D. Gould, A. Izar, A. W. Weimer, J. L. Falconer, J. W. Medlin, ACS Catal., 2014, 4, 2714-2717.

[78] X. G. Zheng, S. Y. Tan, L. C. Dong, S. B. Li, H. M. Chen, Int. J. Hydrogen Energy, 2014, 39, 11360-11367.

[79] K. M. Kang, H. W. Kim, I. W. Shim, H. Y. Kwak, Fuel Process. Technol., 2011, 92, 1236-1243.

[80] Z. W. Li, L. Y. Mo, Y. Kathiraser, S. Kawi, ACS Catal., 2014, 4, 1526-1536.

[81] W. W. Yang, H. M. Liu, Y. M. Li, J. Zhang, H. Wu, D. H. He, Catal. Today, 2016, 259, Part 2, 438-445.

[82] S. S. Bharadwaj, L. D. Schmidt, Fuel Process. Technol., 1995, 42, 109-127.

[83] H. W. Kim, K. M. Kang, H. Y. Kwak, Int. J. Hydrogen Energy, 2009, 34, 3351-3359.

[84] L. Li, Y. Yao, B. Sun, Z. Y. Fei, H. Xia, J. Zhao, W. J. Ji, C. T. Au, ChemCatChem, 2013, 5, 3781-3787.

[85] M. Matsuoka, M. Kitano, M. Takeuchi, K. Tsujimaru, M. Anpo, J. M. Thomas, Catal. Today, 2007, 122, 51-61.

[86] I. Paramasivam, S. Singh, M. Moll, C. Hauser, K. Meyer, P. Schmuki, Electrochim. Acta, 2012, 66, 7-11.

[87] X. F. Cui, G. Y. Jiang, M. Zhu, Z. Zhao, L. C. Du, Y. X. Weng, C. M. Xu, D. K. Zhang, Q. L. Zhang, Y. C. Wei, A. J. Duan, J. Liu, J. S. Gao, Int. J. Hydrogen Energy, 2013, 38, 9065-9073.

[88] T. C. Yang, F. C. Chang, H. P. Wang, Y. L. Wei, C. J. Jou, Mar. Pollut. Bull., 2014, 85, 696-699.

[89] H. S. Kim, D. J. Kim, B. S. Kwak, G. B. Han, M. H. Um, M. Kang, Chem. Eng. J., 2014, 243, 272-279.

[90] A. A. Ismail, D. W. Bahnemann, Sol. Energy Mater. Sol. Cells, 2014, 128, 85-101.

[91] X. B. Li, J. Liu, A. F. Masters, V. K. Pareek, T. Maschmeyer, APL Mater., 2013, 1, 041101.

[92] D. A. Wang, T. Hisatomi, T. Takata, C. S. Pan, M. Katayama, J. Kubota, K. Domen, Angew. Chem. Int. Ed., 2013, 52, 11252-11256.

[93] S. Hernández, V. Cauda, D. Hidalgo, V. Farías Rivera, D. Manfredi, A. Chiodoni, F. C. Pirri, J. Alloys Compd., 2014, 615, S530-S537.

[94] I. Lee, M. A. Albiter, Q. Zhang, J. P. Ge, Y. D. Yin, F. Zaera, Phys. Chem. Chem. Phys., 2011, 13, 2449-2456.

[95] Q. Wang, T. Hisatomi, S. S. K. Ma, Y. B. Li, K. Domen, Chem. Mater., 2014, 26, 4144-4150.

[96] K. Maeda, K. Teramura, D. L. Lu, N. Saito, Y. Inoue, K. Domen, Angew. Chem. Int. Ed., 2006, 45, 7806-7809.

[97] Y. Pihosh, I. Turkevych, K. Mawatari, N. Fukuda, R. Ohta, M. Tosa, K. Shimamura, E. G. Villora, T. Kitamori, Nanotechnology, 2014, $25,315402$.

[98] M. G. Wang, J. Han, H. X. Xiong, R. Guo, Langmuir, 2015, 31, 6220-6228.

[99] G. S. Li, P. Zhang, Z. F. Bian, J. Zhu, L. Wu, H. X. Li, ChemSusChem, 2013, 6, 1461-1466.

[100] Q. Q. Zhang, H. Bai, Q. Zhang, Q. Ma, Y. H. Li, C. Q. Wan, G. C. Xi, Nano Res., 2016, 9, 3038-3047.

[101] B. Liang, N. Zhang, C. Chen, X. H. Liu, R. Z. Ma, S. F. Tong, Z. W. Mei, V. A. L. Roy, H. Y. Wang, Y. G. Tang, Catal. Sci. Technol., 2017, 7, 1000-1005.

[102] J. G. Yu, K. Wang, W. Xiao, B. Cheng, Phys. Chem. Chem. Phys., 2014, 16, 11492-11501. 
[103] S. Das, W. M. A. Wan Daud, Renewable Sustainable Energy Rev., 2014, 39, 765-805.

[104] K. Adachi, K. Ohta, T. Mizuno, Solar Energy, 1994, 53, 187-190.

[105] R. K. de Richter, T. Z. Ming, S. Caillol, Renewable Sustainable Energy Rev., 2013, 19, 82-106.

[106] E. S. Baeissa, Ceram. Int., 2014, 40, 12431-12438.

[107] W. G. Tu, Y. Zhou, H. J. Li, P. Li, Z. G. Zou, Nanoscale, 2015, 7, 14232-14236.

[108] Q. G. Zhai, S. J. Xie, W. Q. Fan, Q. H. Zhang, Y. Wang, W. P. Deng, Y. Wang, Angew. Chem. Int. Ed., 2013, 52, 5776-5779.

[109] C. W. Tsai, H. M. Chen, R. S. Liu, K. Asakura, T. S. Chan, J. Phys. Chem. C, 2011, 115, 10180-10186.

[110] M. M. Gui, W. M. P. Wong, S. P. Chai, A. R. Mohamed, Chem. Eng. J., 2015, 278, 272-278.

[111] S. W. Liu, J. Q. Xia, J. G. Yu, ACS Appl. Mater. Interfaces, 2015, 7, 8166-8175

[112] W. K. Wang, D. F. Xu, B. Cheng, J. G. Yu, C. J. Jiang, J. Mater. Chem. A, 2017. 5, 5020-5029.

[113] X. Wang, M. Y. Liao, Y. T. Zhong, J. Y. Zheng, W. Tian, T. Y. Zhai, C. Y. Zhi, Y. Ma, J. N. Yao, Y. Bando, D. Golberg, Adv. Mater., 2012, 24, 3421-3425.

[114] Z. F. Jiang, W. Wei, D. J. Mao, C. Chen, Y. F. Shi, X. M. Lv, J. M. Xie, Nanoscale, 2015, 7, 784-797.

[115] J. L. Li, X. J. Liu, Z. Sun, Y. Sun, L. K. Pan, J. Colloid Interface Sci,, 2015, 452, 109-115.

[116] J. Zhou, L. Xu, J. L. Sun, D. P. He, H. Jiao, Surf. Coat. Technol., 2015, $271,119-126$

[117] L. L. Chen, L. Li, T. T. Wang, L. Y. Zhang, S. X. Xing, C. G. Wang, Z. M. Su, Nanoscale, 2014, 6, 6603-6608.

[118] J. B. Joo, H. Y. Liu, Y. J. Lee, M. Dahl, H. X. Yu, F. Zaera, Y. D. Yin, Catal. Today, 2016, 264, 261-269.

[119] Y. L. Zhao, C. R. Tao, G. Xiao, G. P. Wei, L. H. Li, C. X. Liu, H. J. Su, Nanoscale, 2016, 8, 5313-5326.

[120] J. Tang, J. Liu, N. L. Torad, T. Kimura, Y. Yamauchi, Nano Today, 2014, 9, 305-323

[121] H. Y. Zhang, H. J. Wang, K. Eid, L. Wang, Part. Part. Syst. Charact., 2015, 32, 863-868.

[122] L. Z. Gu, L. H. Jiang, J. T. Jin, J. Liu, G. Q. Sun, Carbon, 2015, 82, 572-578.

[123] K. Selvakumar, S. M. Senthil Kumar, R. Thangamuthu, G. Kruthika, P. Murugan, Int. J. Hydrogen Energy, 2014, 39, 21024-21036.
[124] J. W. Xiao, C. Chen, J. B. Xi, Y. Y. Xu, F. Xiao, S. Wang, S. H. Yang, Nanoscale, 2015, 7, 7056-7064.

[125] F. B. Su, Z. C. Zhou, W. P. Guo, J. J. Liu, X. N. Tian, X. S. Zhao, in Chemistry \& Physics of Carbon, L. R. Radovic eds., CRC Press, 2007, 63-128.

[126] L. Kuai, S. Z. Wang, B. Y. Geng, Chem. Commun., 2011, 47, 6093-6095

[127] S. H. Ye, X. J. He, L. X. Ding, Z. W. Pan, Y. X. Tong, M. M. Wu, G. R. Li, Chem. Commun., 2014, 50, 12337-12340.

[128] N. V. Long, Y. Yang, C. Minh Thi, N. V. Minh, Y. Q. Cao, M. Nogami, Nano Energy, 2013, 2, 636-676.

[129] Y. Q. Huang, Y. J. Liu, Z. H. Yang, J. L. Jia, X. Li, Y. Luo, Y. P. Fang, J. Power Sources, 2014, 246, 868-875.

[130] X. G. Li, G. Liu, B. N. Popov, J. Power Sources, 2010, 195, 6373-6378.

[131] Q. R. Shi, P. N. Zhang, Y. J. Li, H. B. Xia, D. Y. Wang, X. T. Tao, Chem. Sci., 2015, 6, 4350-4357.

[132] Y. X. Ye, L. Kuai, B. Y. Geng, J. Mater. Chem., 2012, 22, 19132-19138.

[133] Y. Z. Lu, Y. Y. Jiang, X. H. Gao, X. D. Wang, W. Chen, Part. Part. Syst. Charact., 2016, 33, 560-568.

[134] H. Hu, B. Y. Guan, B. Y. Xia, X. W. Lou, J. Am. Chem. Soc., 2015, 137, 5590-5595.

[135] H. Hu, L. Han, M. Z. Yu, Z. Y. Wang, X. W. Lou, Energy Environ. Sci, 2016, 9, 107-111.

[136] S. J. Chao, Q. Cui, K. Wang, Z. Y. Bai, L. Yang, J. L. Qiao, J. Power Sources, 2015, 288, 128-135.

[137] S. Y. Bie, Y. Q. Zhu, J. M. Su, C. Jin, S. H. Liu, R. Z. Yang, J. Wu, J. Mater. Chem. A, 2015, 3, 22448-22453.

[138] X. J. Zheng, X. C. Cao, J. Wu, J. H. Tian, C. Jin, R. Z. Yang, Carbon, 2016, 107, 907-916.

[139] Z. X. Yin, C. L. Zhu, C. Y. Li, S. Zhang, X. T. Zhang, Y. J. Chen, Nanoscale, 2016, 8, 19129-19138.

[140] H. Tian, S. C. Wang, C. Zhang, J. P. Veder, J. Pan, M. Jaroniec, L. Z. Wang, J. Liu, J. Mater. Chem. A, 2017. In Press

[141] Y. J. Hao, X. Jiao, H. B. Zou, H. Q. Yang, J. Liu, J. Mater. Chem. A, 2017. In Press

[142] Z. W. Wang, Y. X. Liu, T. Yang, J. G. Deng, S. H. Xie, H. X. Dai, Chin. J. Catal., 2017, 38, 207-216.

[143] S. Mortazavi-Derazkola, M. Salavati-Niasari, O. Amiri, A. Abbasi, J. Energy Chem., 2017, 26, 17-23.

\title{
先进蛋黄-蛋壳结构能源转化纳米反应器
}

\author{
王美文, Yash Boyjoo, 潘 剑, 王少涁\#, 刘 健 ${ }^{*}$ \\ 澳大利亚科廷大学化学工程系, 珀斯6845, 澳大利亚
}

摘要: 蛋黄-蛋壳结构独特的纳米结构及特性, 使其在很多领域中具有潜在的应用价值, 因此近年来受到了广泛关注. 本综 述总结了使用蛋黄-蛋壳纳米结构作为纳米反应器的研究进展. 从合成策略出发, 主要强调最近五年合成蛋黄-蛋壳纳米结 构的最新研究进展. 通过光催化, 甲烷重整和电催化等反应作为典型的反应过程, 重点讨论蛋黄-蛋壳结构纳米反应器在催 化领域的应用, 并对该领域未来的发展进行了展望.

关键词: 蛋黄-蛋壳结构纳米反应器; 能源转化应用; 光催化; 燃料电池; 碳资源综合利用

收稿日期: 2016-10-28. 接受日期: 2017-03-13. 出版日期: 2017-06-05.

*通讯联系人. 电子信箱: jian.liu@curtin.edu.au

\#通讯联系人。电子信箱: shaobin.wang@exchange.curtin.edu.au

本文的英文电子版由Elsevier出版社在ScienceDirect上出版(http://www.sciencedirect.com/science/journal/18722067). 